Article

\title{
A Fermented Food Product Containing Lactic Acid Bacteria Protects ZDF Rats from the Development of Type 2 Diabetes
}

\author{
Miriam Cabello-Olmo ${ }^{1}\left[\right.$, Maria Oneca ${ }^{1}$, Paloma Torre ${ }^{2}$, Neira Sainz ${ }^{3}$, \\ María J. Moreno-Aliaga ${ }^{3,4,5}$, Elizabeth Guruceaga ${ }^{5,6}{ }^{\oplus}$, Jesús Vicente Díaz ${ }^{7}$, \\ Ignacio J. Encio ${ }^{1}\left(\mathbb{D}\right.$, Miguel Barajas ${ }^{1, *,+}$ and Miriam Araña ${ }^{1, *,+}(\mathbb{D}$ \\ 1 Biochemistry Area, Department of Health Science, Public University of Navarre, 31008 Pamplona, Spain; \\ miriamcabelloolmo@gmail.com (M.C.-O.); maria.oneca@unavarra.es (M.O.); \\ ignacio.encio@unavarra.es (I.J.E.) \\ 2 Nutrition and Bromatology area, Department of Natural Sciences, Public University of Navarre, \\ 31006 Pamplona, Spain; paloma@unavarra.es \\ 3 Department of Nutrition Food Sciences and Physiology, Center for Nutrition Research, \\ University of Navarra, 31008 Pamplona, Spain; nsainz@unav.es (N.S.); mjmoreno@unav.es (M.J.M.-A.) \\ 4 CIBERobn Physiopathology of Obesity and Nutrition, Centre of Biomedical Research Network, ISCIII, \\ 28029 Madrid, Spain \\ 5 IDISNA, Navarra's Health Research Institute, 31008 Pamplona, Spain; eguruce@unav.es \\ 6 Bioinformatics Platform, Center for Applied Medical Research, University of Navarra, \\ 31008 Pamplona, Spain \\ 7 Pentabiol S.L., Polígono Noain-Esquiroz s/n, 31191 Pamplona, Spain; jesus@pentabiol.es \\ * Correspondence: miguel.barajas@unavarra.es (M.B.); miriam.arana@unavarra.es (M.A.); \\ Tel.: +34-948-169 00 (M.A. \& M.B.) \\ + These authors contributed equally to this work.
}

Received: 11 September 2019; Accepted: 15 October 2019; Published: 20 October 2019 updates

\begin{abstract}
Type 2 diabetes (T2D) is a complex metabolic disease, which involves a maintained hyperglycemia due to the development of an insulin resistance process. Among multiple risk factors, host intestinal microbiota has received increasing attention in T2D etiology and progression. In the present study, we have explored the effect of long-term supplementation with a non-dairy fermented food product (FFP) in Zucker Diabetic and Fatty (ZDF) rats T2D model. The supplementation with FFP induced an improvement in glucose homeostasis according to the results obtained from fasting blood glucose levels, glucose tolerance test, and pancreatic function. Importantly, a significantly reduced intestinal glucose absorption was found in the FFP-treated rats. Supplemented animals also showed a greater survival suggesting a better health status as a result of the FFP intake. Some dissimilarities have been observed in the gut microbiota population between control and FFP-treated rats, and interestingly a tendency for better cardiometabolic markers values was appreciated in this group. However, no significant differences were observed in body weight, body composition, or food intake between groups. These findings suggest that FFP induced gut microbiota modifications in ZDF rats that improved glucose metabolism and protected from T2D development.
\end{abstract}

Keywords: diabetes; fermented food; gut microbiota; lactic acid bacteria; postbiotic; probiotic

\section{Introduction}

Type 2 diabetes (T2D) is characterized by a chronic hyperglycemia preceded by a deranged insulin sensitivity and/or synthesis. This chronic non-communicable disease accounts for the vast majority of cases of diabetes, more than $90 \%$ [1], being one of the most prevalent illnesses. Importantly, 
T2D is associated with over $70 \%$ of global deaths [2]. Genetic factors contribution is unlikely to be responsible for the increasing T2D incidence because of the genome stability, although physicians and the scientific community have also focused on environmental factors [3,4]. One possible explanation hypothesizes the role of microorganisms that coexist with us [5]. The gut microbiota (GM) is the bigger reservoir ( $10^{14}$ microbes) [5] and is considered an organ because of its crucial metabolic and defense competences [6]. Its anomalous distribution or activity, named dysbiosis [7], has been related to a wide group of illnesses and physiopathological conditions [8]. Specifically, there is evidence that diabetes occurs in association with a compromised gut environment and a large body of research highlights a plausible connection between T2D and GM [9-11]. For instance, a compromised abundance of beneficial bacteria [12] or increase of infrequent species [13] have been reported in T2D and obese individuals.

The GM displays some plasticity and different strategies resulted in marked changes. Among the studied approaches, dietary modulation was successful in causing significant changes in the GM $[13,14]$. Probiotics, prebiotics, symbiotics, and fermented foods are known to confer health benefits on the host by improving GM performance and have been proposed as novel clinical strategies for T2D $[6,15,16]$. For instance, probiotic supplementation with Lactobacillus G15 and Q14 showed improved glucose tolerance in streptozotocin (STZ)-induced type 2 diabetic rats [17]. Human intervention studies have also shown good results. A crossover trial with prediabetic individuals reported a reduced insulin resistance after kimchi consumption [18], and a randomized controlled trial in T2D subjects supplemented with a fermented milk with the probiotic Lactobacillus casei strain Shirota showed a healthier gut ecosystem with strengthened gut barrier function along with modulation of microbial communities [19].

The most widespread fermented products are dairy products like yogurt, kefir, or dahi. Nonetheless, other food matrixes like fruits, vegetables, or cereals have also been studied and showed many beneficial effects on health [20]. Indeed, some attractive advantages over dairy products have been described for them [21]. In the present study we have tested the effectiveness of a non-dairy fermented food product (FFP) in preventing the T2D and obese phenotype developed by the Zucker diabetic fatty (ZDF) rat model. This murine model presents a mutation in the leptin receptor accompanied with an enhanced $\beta$-cell destruction and impaired glucose homeostasis, and is a widely used model for T2D studies [22,23]. Previous research reported the effectiveness of probiotics in the attenuation of the diabetic and obese phenotype in ZDF rat model [24] and other rodent models $[25,26]$. However, few researchers have tested the efficiency of fermented food on the diabetic phenotype and previous works have only focused on dairy products [27]. On top of this, the literature on probiotic microorganisms indicates that the functional attributes of the cells are to a large degree dependent on the strain $[28,29]$. Therefore, an individual characterization should be performed for each study product. Our fermented food product derives from a fermented feed, which has previously demonstrated the ability to improve health and wellness in farm animals (HEALTHSTOCK Ref. 733627; https://cordis.europa.eu/project/rcn/206082/factsheet/es). Consequently, FFP has been used in a controlled in vivo study (ZDF rat model) in order to demonstrate its benefit in glycemic control and in comorbidities derived from hyperglycemia.

\section{Materials and Methods}

\subsection{Product Description}

The fermented food product tested is a plant-based food product primarily composed by soya flour, alfalfa meal, and barley sprouts along with other minor components (including skimmed milk powder). The FFP is defined as a non-probiotic product classified as fermented food [29]. During the production process a combination of specific LABs and non-bitter beer yeast is incorporated to the raw materials and a classical fermentation process is performed. The FFP has been produced using standard culture medium Tryptic Soya Agar (TSA) in microaerophilic conditions at $37^{\circ} \mathrm{C}$ until microorganisms 
concentration achieve at least $10^{9}$ microorganisms $/ \mathrm{mL}$ in an exponential growth phase or close to the stationary phase. The manufacturing as well as the pool of microorganisms intentionally added are responsible for the viable microorganisms and composition of the final product (Tables S1 and S2). The FFP is presented as a dry granulated product, with an average particle size ranging from 4 to $12 \mathrm{~mm}$ (Figure S1) with a moisture content of $12.8 \%$ and a pH of 4.4. The metagenomics analysis revealed that Firmicutes is the most predominant phylum (38.7\%), followed by Proteobacteria (26.7\%), Bacteroidetes $(18.3 \%)$, Actinobacteria (14.5\%), and lately TM7 (1.8\%). At genus level, Lactobacillus are the most predominant accounting for more than $6 \%$ of identified species.

\subsection{Animals and Experimental Design}

Eleven weeks-old male ZDF rats ( $n=16$ ) (Charles River Laboratories) were acclimated for five weeks and housed in a controlled environment (a room with constant temperature and humidity under a 12:12 $\mathrm{h}$ light-dark cycle) with ad libitum access to food (standard rodent chow) and water. Animals were randomly divided and allocated into two groups: A control group (C group) $(n=8)$ and a group supplemented with FFP (T group) $(n=8)$. ZDF rats were housed at four animals per cage. After the acclimatization period, all animals were given hypercaloric diet (HD) (TD.06416; Envigo) until the end of the study, which lasted 31 weeks (see composition of HD in Table S2). The T group was additionally fed with FFP (200 g per cage and week). See the experimental design scheme (Figure S2). The glucose uptake assay, the insulin positive cell quantification such as the analysis of the microbiota were analyzed by blinded investigators.

Animal procedures were performed in accordance with the "Principles of Laboratory Animal Care" formulated by the National Society for Medical Research and the "Guide for the Care and Use of Laboratory Animals" prepared by the Institute of Laboratory Animal Resources, Commission on Life Science, National Research Council, and published by the National Academy Press, revised 1996. All animal procedures were approved by the Institutional Committee on Care and Use of Laboratory Animals (CEEA, University of Navarra) (Protocol number: CEEA/117-15).

\subsection{Fasting Blood Glucose and Intraperitoneal Glucose Tolerance Test}

Animals were fasted $24 \mathrm{~h}$ and blood samples were collected from the tip of the tail vein in order to determine blood glucose levels by using a glucometer (Accu-chek Aviva, Roche, Basel, Switzerland). Fasting blood glucose (FBG) was recorded once a week.

For glucose tolerance test (GTT) determination, $24 \mathrm{~h}$ fasted animals received glucose (Baxter, Valencia) intraperitoneally (1.5 g/kg of body weight) and glycemia was determined as described for FBG at different time points (baseline, 20, 40, 60, 90, 120, and $150 \mathrm{~min}$ ) after glucose injection. GTT was conducted at one and two months after the start of the study. The area under the curve (AUC) of glucose values was assessed for each group from 0 to $150 \mathrm{~min}$ post glucose injection.

\subsection{Body Weight, Food Intake and Body Composition}

Body weight (BW) was measured once a week with an electronic balance. HD food intake was monitored weekly for 12 weeks. The weekly HD intake mean was estimated for the two experimental groups as grams per week and animal. Also, body composition was determined for each group ( $n=4$ in C group; $n=5$ in T group) using nuclear magnetic resonance (EchoMRI, EchoMedical Systems, Houston, TX, USA) at the end of the study.

\subsection{Analysis of Functional Properties: C-peptide Synthesis and Intestinal Glucose Uptake Assays}

Blood C-peptide concentration (ng $\mathrm{mL}^{-1}$ ) was quantified with a commercial C-Peptide ELISA kit (Crystal Chem Europe) at time points four and seven months from the beginning of the study. HOMA-IR and HOMA- $\beta$ were determined at the end of the study. HOMA-IR was calculated by the formula: HOMA-IR = serum C-peptide $\left(\mathrm{ng} \mathrm{mL}^{-1}\right)^{*}$ blood glucose $\left(\mathrm{mmol} \mathrm{L}^{-1}\right) / 22.5$; and HOMA- $\beta$ was calculated by the formula: HOMA- $\beta=20^{*}$ serum C-peptide $\left(\mathrm{ng} \mathrm{mL} \mathrm{L}^{-1}\right) /\left(\right.$ blood glucose $\left.\left(\mathrm{mmol} \mathrm{L}^{-1}\right)-0.35\right)$. 
The effects of in vivo FFP supplementation on the uptake of $\alpha$-Methyl-D-glucoside ( $\alpha$-MG), a SGLT-1 specific substrate, were determined on everted jejunal rings obtained from the animals as previously described [30]. Briefly, at the end of the study, animals were sacrificed, the jejunum obtained, and groups of six rings were incubated at $37^{\circ} \mathrm{C}$ for 15 min under continuous shaking in Krebs-Ringer-Tris (KRT) solution gassed with $\mathrm{O}_{2}$. The solution contained $1 \mathrm{mM} \alpha$-MG and $0.0025 \mu \mathrm{Ci} \mathrm{mL}{ }^{-1}$ of $\left[{ }^{14} \mathrm{C}\right] \alpha-\mathrm{MG}$ (Ge Healthcare, Little Chalfont, UK). At the end of the incubation period, rings were removed from the medium, weighed, and the accumulated substrate was extracted from the rings for $15 \mathrm{~h}$ in $0.1 \mathrm{M} \mathrm{HNO}_{3}$ at $4{ }^{\circ} \mathrm{C}$. Finally, duplicate aliquot samples were taken for liquid scintillation counting. $\alpha-\mathrm{MG}$ uptake was estimated from the relationship between the counts per minute recorded for the incubation medium and the counts per minute obtained for the $\mathrm{HNO}_{3}$ aliquots and expressed as micromoles of $\alpha-\mathrm{MG}$ per gram of wet weight (w.w.) per $15 \mathrm{~min}$.

\subsection{Lipid Profile and Hepatotoxicity Markers}

In order to determine the lipid profile, fasting blood samples were extracted from the dorsal pedal vein under anesthesia ( $5 \%$ isoflurane in oxygen) at baseline, two, four, and seven months of the study. Samples were centrifuged $15 \mathrm{~min}$ at $13,000 \mathrm{rpm}$ and stored at $-80{ }^{\circ} \mathrm{C}$ for biochemical analysis. Also, serum total cholesterol (TC), high-density lipoprotein (HDL-C), low-density lipoprotein (LDL-C), triglycerides (TG) and aspartate and alanine amino-transferases (AST and ALT, respectively) were analyzed (Cobas c311 analyzer, Roche, Basel, Switzerland). The atherogenic index (AI) was estimated using the formula $\log (\mathrm{TG} / \mathrm{HDL}-\mathrm{C})$ as previously described [31].

\subsection{Tissue Collection and Histological Analysis}

After 31 weeks of study, o/n fasting animals were sacrificed by decapitation. The pancreas and fat tissues (retroperitoneal, epidydimal, mesenteric, subcutaneous, and brown fat) were immediately removed, weighted, and fixed in $10 \%$ buffered formalin.

Fixed pancreas samples were embedded in paraffin blocks, cut at a thickness of $3 \mu \mathrm{m}$ and analyzed by immunohistochemistry ( $n=4$ for each group). Immunolabelling was performed with an antibody against insulin (dilution 1:8000, A0564 Dako) and a secondary antibody labeled with HRP (dilution 1:100, P0141 Dako). All sections were observed under an optical microscope using the $10 \times$ objective lens (Olympus $\mathrm{CH}$, Shinjuku, Japan) and insulin positive cells were counted. Nine serial sections were analyzed for each pancreas.

The total area $\left(\mathrm{mm}^{2}\right)$ of the analyzed sections was calculated. For this purpose, slides containing the stained histological samples were digitized (APERIO CS2, Leica Biosystems, San Diego, CA, USA) and images were analyzed using the ImageJ 1.52 software. The results of the quantification are shown as insulin-positive cells per pancreas area (insulin positive cells $/ \mathrm{mm}^{2}$ ) at the end of the study.

\subsection{Faecal Microbiota Analysis}

Rat feces were collected at six months of study and immediately frozen at $-80{ }^{\circ} \mathrm{C}$ for the purpose of metagenomic analysis. 16S rRNA sequences obtained were filtered following quality criteria of the OTU processing pipeline LotuS (release 1.58) [32]. This pipeline includes UPARSE de novo sequence clustering [33], removal of chimeric sequences and phix contaminants for the identification of operational taxonomic units (OTUs), and OTU abundance matrix generation. Finally, taxonomy was assigned using BLAST [34] and HITdb [35] achieving up to species-level sensitivity. The abundance matrices were first filtered and then normalized in R/Bioconductor [36] at each classification level: OTU, species, genus, family, order, class, and phylum. Briefly, taxa were discarded for future analysis when less than four reads were obtained in more than $50 \%$ of the samples of both experimental conditions, and a global normalization was performed using the library size as a correcting factor and $\log 2$ data transformation. Linear models for microarray data (LIMMA) [37] was used to identify taxa with significant differential abundance between experimental conditions. The selection criteria was 
based on an FDR cut-off (FDR < 0.05). Further clustering analyses and graphical representations were performed using R/Bioconductor [36].

\subsection{Statistical Analysis}

Statistical analysis was performed with the SPSS 22.0 for windows software package. Normality and variances homogeneity were tested with the Shapiro-Wilk and Levene tests, respectively. For values showing normal distribution, comparisons were carried out using unpaired and paired Student's T-test and in case of non-normal distribution, U-Mann-Whitney test. Results are expressed as mean \pm standard deviation (SD). Statistical significance was set at $p<0.05$ and $p<0.01$ was considered as highly significant.

\section{Results}

\subsection{FFP Supplementation Leads to Lower Fasting Blood Glucose Levels and Improves Glucose Tolerance}

In order to determine the effectiveness of FFP supplementation to control blood glucose levels in ZDF rats supplemented with HD we have performed a FBG determination on ZDF rats fasted during $24 \mathrm{~h}$. No significant differences between groups were observed in FBG values basally (Figure 1A). However, after four weeks of supplementation, animals in the T group exhibited lower FBG values than animals in the $C$ group $\left(8.0 \pm 1.8\right.$ versus $12.0 \pm 2.7 \mathrm{mmol} \mathrm{L}^{-1}$, respectively; $\left.p=0.004\right)$. Statistical significant differences between groups were also found in week six $(p=0.038)$, week $14(p=0.013)$, week $16(p=0.013)$, week $21(p=0.005)$, week $22(p=0.026)$, week $24(p=0.001)$, week $27(p=0.03)$, week $28(p=0.001)$, and week $31(p=0.016)$ as represented in Figure 1A. Initial and final FBG values were compared in the $C$ group showing no statistical significant differences, despite the observed differences were very high $(p=0.125)$; on the other hand, initial and final FBG values in the T group are comparable and no statistically significant differences were found ( $p=0.625)$ (Figure 1B). Although, one-month period was not enough to display significant differences in GTT between groups (data not shown), after two months of supplementation, the $\mathrm{T}$ group showed lower glycemic values versus the $C$ group although not all the time points showed significance (Figure 1C). Statistically significant differences were found at GTT time point $20 \mathrm{~min}(p=0.034), 40 \mathrm{~min}(p=0.007)$ and $120 \mathrm{~min}(p=0.038)$ time points of the GTT. Glucose AUC showed higher values in the C group with a $p$ value in the limit of significance $(p=0.05$ ) (Figure 1D). These findings suggest that rats supplemented with the FFP exhibited a better glucose metabolism control than those fed exclusively with HD (C group).

A

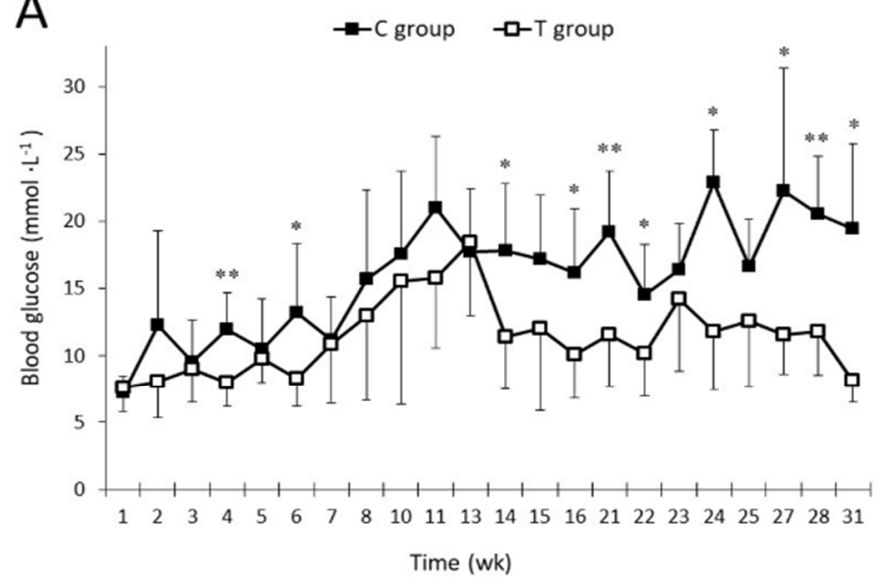

B

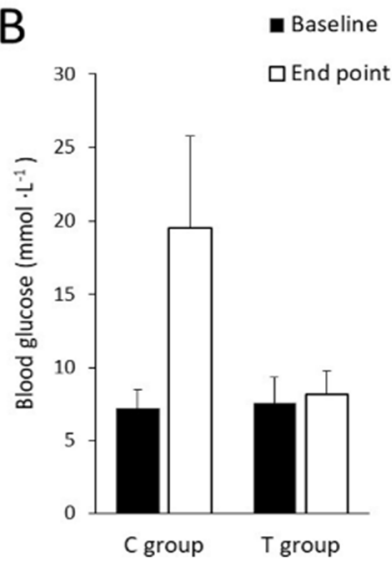

Figure 1. Cont. 

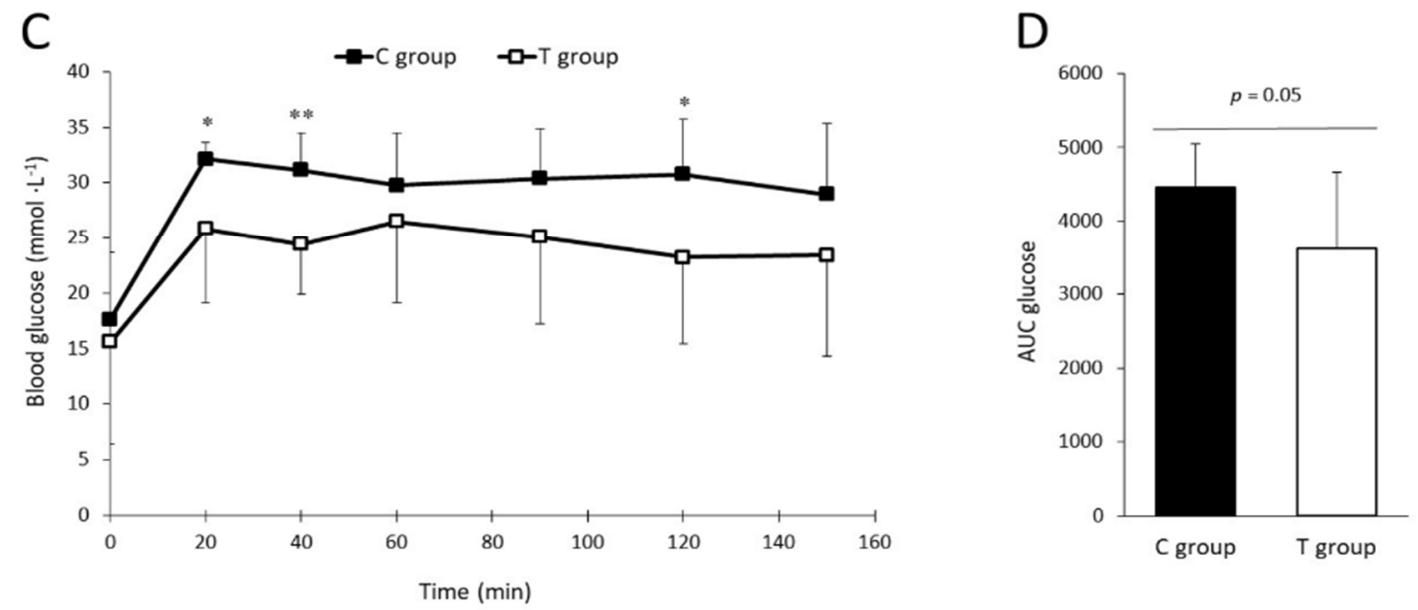

Figure 1. Effect of the fermented food product (FFP) on glucose metabolism. (A) Weekly fasting blood glucose (FBG) progression in Zucker diabetic fatty (ZDF) rats. Animals in T group showed lower FBG mean values than animals in $C$ group during the study. Statistically significant differences were found at $4,6,14,16,21,22,24,27,28$, and 31 weeks ( $p=0.004, p=0.038, p=0.013, p=0.013$, $p=0.005, p=0.026, p=0.001, p=0.030, p=0.001$, and $p=0.016$, respectively). (B) Bar plots represent basal and end point FBG values in the groups. No statistical significant differences were found between basal and end point FBG values in any groups $\left(7.2 \pm 1.3\right.$ versus $19.5 \pm 6.3 \mathrm{mmol} \mathrm{L}^{-1}$ at 0 and 31 weeks, respectively in C group; $7.6 \pm 1.8$ versus $8.2 \pm 1.6 \mathrm{mmol} \mathrm{L}^{-1}$ at 0 and 31 weeks respectively in T group). (C) Two-months glucose tolerance test (GTT) curve. The GTT curve, after two months of FFP supplementation, showed lower blood glucose levels and statistically significant differences between groups were found at 20,40, and $120 \mathrm{~min}(p=0.034, p=0.007$, and $p=0.038$, respectively). (D) Area under the curve (AUC) plot. The AUC value was lower in T group (3622.5 \pm 1040.4$)$ compared to $C$ group ( $4454.0 \pm 590.9)$ although the $p$ value obtained was in the limit of significance $(p=0.05)$. Values are expressed as mean $\pm \mathrm{SD}$. wk $=$ week. ${ }^{*} p<0.05,{ }^{* *} p<0.01$.

\subsection{Body Weight, Body Composition, and Food Intake after FFP Consumption}

Initial body weight values were similar between groups $(p=0.610)$ and BW increase was steady and similar within the groups during the first eight weeks of study, time at which different trends were observed between groups. From week eight onward, the $\mathrm{T}$ group continued gaining weight whereas the $C$ group did not increase BW and even a weight loss was observed at the end of the study (Figure 2A).

Regarding the BW gain (difference between end point and basal BW values), statistically significant differences were observed in the T group $(p=0.031)$, while the $C$ group did not experiment statistical significant changes over time $(p=0.625)$ (Figure 2B).

No statistically significant differences were found in HD food consumption between both groups $(p=0.413)$ (Figure 2C). Interestingly, data on food intake differs from the outcomes found in BW, which indicates that animals supplemented with the FFP showed a greater BW gain.

Body composition was evaluated before sacrifice and despite the asymmetry of BW found at the end of the study, no statistically significant differences within groups were assessed in fat mass percentage $(p=0.630)$. Both groups also exhibited similar mean values of lean mass $(p=0.641)$ and other tissues relative percentage ( $p=0.947$ ) (Figure S3). These results suggest that the supplementation with the FFP did not alter body composition in ZDF rats fed with HD. Supporting the previous presumption, the weights of retroperitoneal, epidydimal, mesenteric, subcutaneous, and brown fat mass collected at sacrifice did not statistically differ between experimental groups (Table S3). 

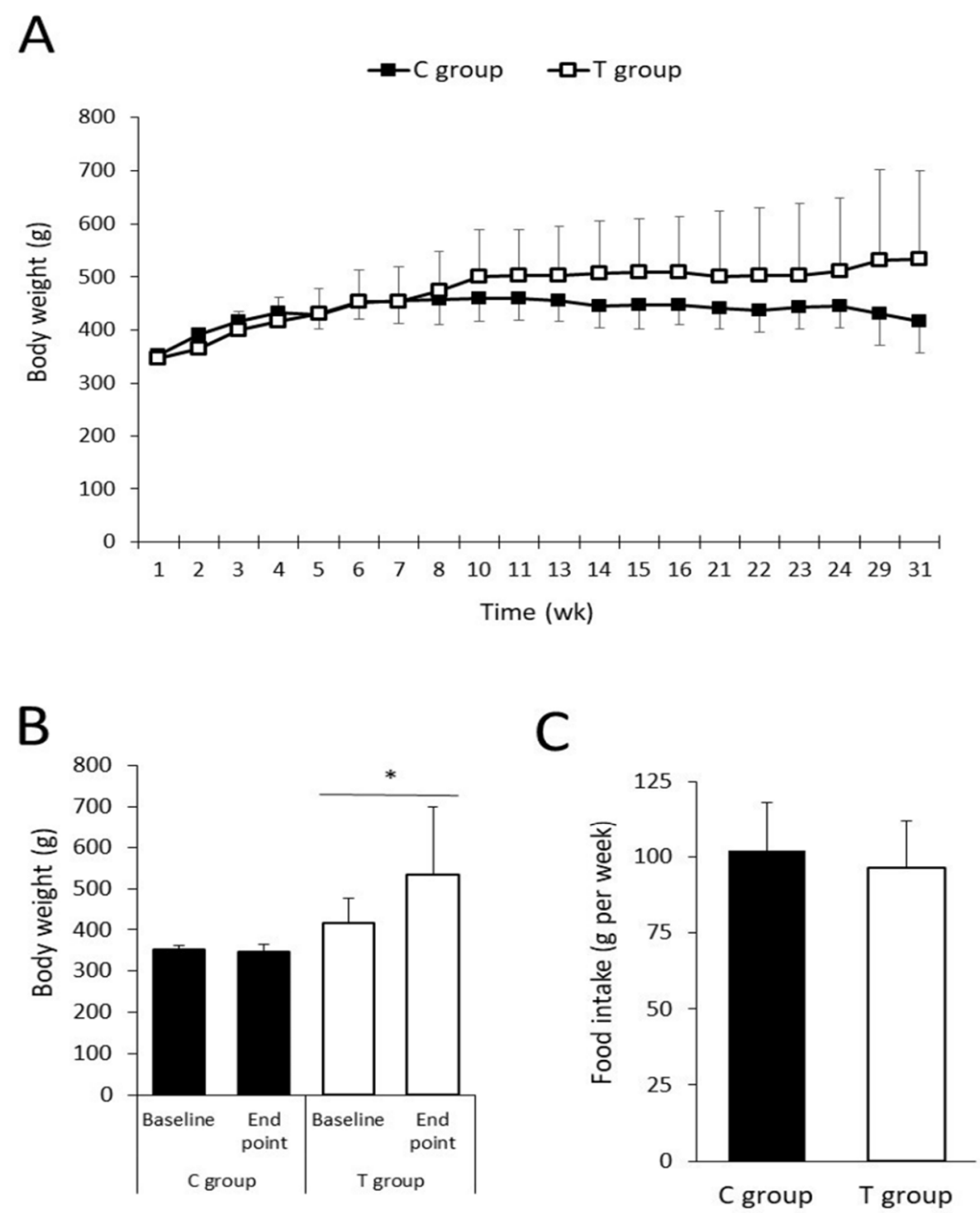

Figure 2. Body weight progression, body weight (BW) gain and average of hypercaloric diet (HD) food intake during the intervention. No statistically significant differences were observed in BW (A) between the experimental groups in spite of their divergent growing tendencies. BW gain (B) was statistically significant in T group (346.0 \pm 18.4 versus $533.5 \pm 165.8 \mathrm{~g}$ at baseline and at the end point, respectively; $p=0.031$ ) but no statistical significant differences were found in C group ( $352.3 \pm 9.9$ versus $416.8 \pm 60.3 \mathrm{~g}$ at baseline and at the end point, respectively; $p=0.625)$. The FFP administration did not alter HD food intake (C), which was comparable in both groups $(101.9 \pm 16.2$ versus $96.5 \pm 15.7 \mathrm{~g}$ in C and T groups, respectively; $p=0.413)$. Values are expressed as mean $\pm \mathrm{SD}$. ${ }^{*} p<0.05$.

\subsection{FFP Preserves Normal Metabolic and Biochemical Parameters}

Comparisons of lipid profile and hepatotoxicity markers between and within groups are available in Table S4. No statistically significant differences were found at baseline in any of the explored parameters between both experimental groups, except for LDL-C $(p=0.021)$ and TG mean values $(p=0.025)$. During the study both groups experimented an increase in LDL-C values and the magnitude was greater in the $C$ group than in the T group ( $p=0.001$ and $p=0.023$, respectively). Although baseline TG levels were significantly lower in the C group $(p=0.025)$, a statistically significant increase was observed for the same group after seven months of study ( $p=0.043$ ) while T group remained unchanged. Indeed, significant differences were appreciated between groups at the end of the trial $(p=0.01)$. Somehow the FFP could restore and normalize TG values. Regarding TC, both C and 
T groups showed the same tendency of increase at the end of the study ( $p=0.00$ and $p=0.011$, respectively) and the same response was found in LDL-C ( $p=0.01$ and $p=0.023$ in the C group and T group, respectively). Taken together, pairwise comparisons between all of the follow-up time points revealed that at the end of the study both groups showed significantly greater serum levels of TC, LDL-C, and HDL.

With respect to the liver function and the stress induced by the HD, serum AST and ALT levels were determined along the intervention as well. For both parameters, statistically significant differences were found between $\mathrm{T}$ and $\mathrm{C}$ groups at two months of study, when a peak on serum AST and ALT was observed: The T group showed significant lower values of both AST and ALT $(p=0.001$ and $p=0.019$, respectively). After the aforementioned peak, transaminase levels were normalized, and such reduction was more pronounced in the group supplemented with FFP (Figure 3A). The AI showed statistically significant differences between groups at baseline $(p=0.023)$ and at the end of the study $(p=0.020)$ (Figure 3B). The T group presented a tendency with a better health status in the T group and when pairwise comparison was made, the treated group exhibited an improved and reduced AI at the end of the study in contrast with its baseline value $(p=0.027)$. Regardless the tendency observed in Figure $3 \mathrm{~B}$ the $\mathrm{C}$ group did not present marked differences on $\mathrm{AI}$ over time.
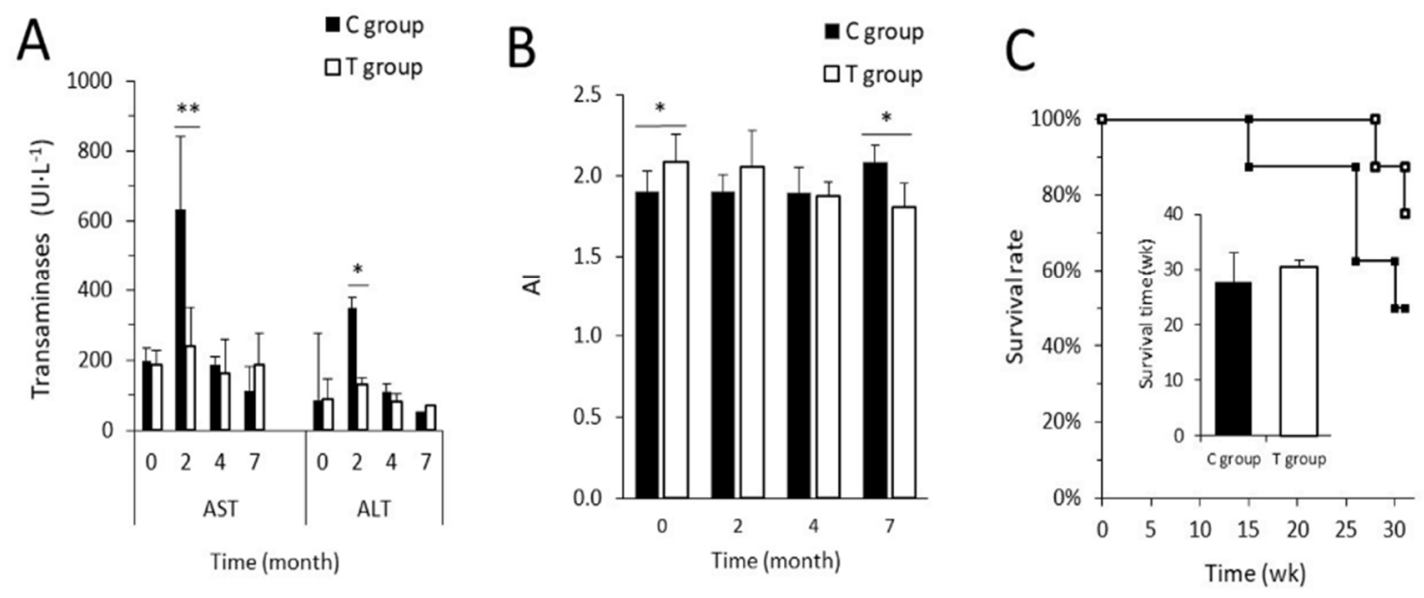

Figure 3. Transaminases level, atherogenic index and survival rate in ZDF rats. (A) Transaminase levels. Statistical significant differences were observed in aspartate and alanine amino-transferases (AST and ALT) at two months of study, being that the C group clearly shown higher concentrations of both AST (632.1 \pm 208.9 versus $238.9 \pm 112.6 \mathrm{UI} \mathrm{L}^{-1}$ in $\mathrm{C}$ and T groups, respectively; $\left.p=0.001\right)$ and $\operatorname{ALT}\left(348.0 \pm 192.2\right.$ versus $90.0 \pm 54.6 \mathrm{UI} \mathrm{L}^{-1}$ in C and T groups, respectively; $\left.p=0.019\right)$. (B) Atherogenic index. Statistically significant differences were observed in basal $(1.9 \pm 0.1$ versus $2.1 \pm 0.1$ in $C$ and $\mathrm{T}$ groups, respectively; $p=0.004)$ and end point values of atherogenic index (AI) $(2.1 \pm 0.2$ versus $1.8 \pm 0.1$ in $\mathrm{C}$ and $\mathrm{T}$ groups, respectively; $p=0.015)$. (C) Kaplan-Meier plot. The T group demonstrated a greater survival rate $(87.5 \%)$ compared to the $\mathrm{C}$ group $(50 \%)$. The survival time was higher in the $\mathrm{T}$ group (27.6 \pm 5.6 versus $30.6 \pm 1.1$ weeks in $C$ and T groups, respectively, $p=0.106)$ but no significant differences between both groups were found. Data are represented as mean \pm SD. ${ }^{*} p<0.05 ;{ }^{* *} p<0.01$.

Overall, the group supplemented with FFP displayed a healthier phenotype, what is also supported by data on survival rate (Figure 3C). Animals in the T group exhibited a tendency of longer life expectancy ( $30.6 \pm 1.1$ weeks) compared to the animals included in the $C$ group ( $27.6 \pm 5.6$ weeks) $(p=0.106)$. Throughout the experimental study, five rats died. The deceased animals presented clear T2D symptoms including a maintained hyperglycemia, marked weight loss, greater water consumption (polydipsia), and wetter cage floor due to increased urine excretion (polyuria) $[1,38,39]$ according to the ZDF animal model disease progression [23]. Four of them belonged to the $C$ group (these rats died at week 15 , week 26 , week 26 , and week 30 of study) and only one to the T group (the rat died at 
week 28 of study). Those results indicate that the supplementation with FFP increase the survival rate at the end of the study ( $87.5 \%$ in the $\mathrm{T}$ group) in contrast to the C group (50\%).

\subsection{The Administration of FFP Allows the Maintenance of Normal Pancreatic Activity}

Blood insulin levels, measured as C-peptide cleavage secretion, were determined at two different time points (four months and seven months) in both groups. The results indicate that although a tendency to protection in the secretion of insulin was observed in the group treated with FFP, no significant differences were found between $\mathrm{T}$ group and $\mathrm{C}$ group at four and seven months ( $p=0.234$ and $p=0.792$, respectively) (Figure $4 \mathrm{~A}$ ). Besides, when looking to the ability to synthetize insulin, no significant differences were detected in the total area of insulin-positive cells of pancreatic tissue in both experimental groups $(p=0.114)$. With the aim of evaluating $\beta$-cells efficiency in insulin synthesis, we assessed the correspondence between the quantified positive $\beta$-cell number and $C$-peptide levels in serum at the end of the study. The results suggest a higher value of $C$-peptide levels $/ \beta$-cell in the T group although no significant differences were found $(p=0.114)$ (Figure $4 \mathrm{~B})$.
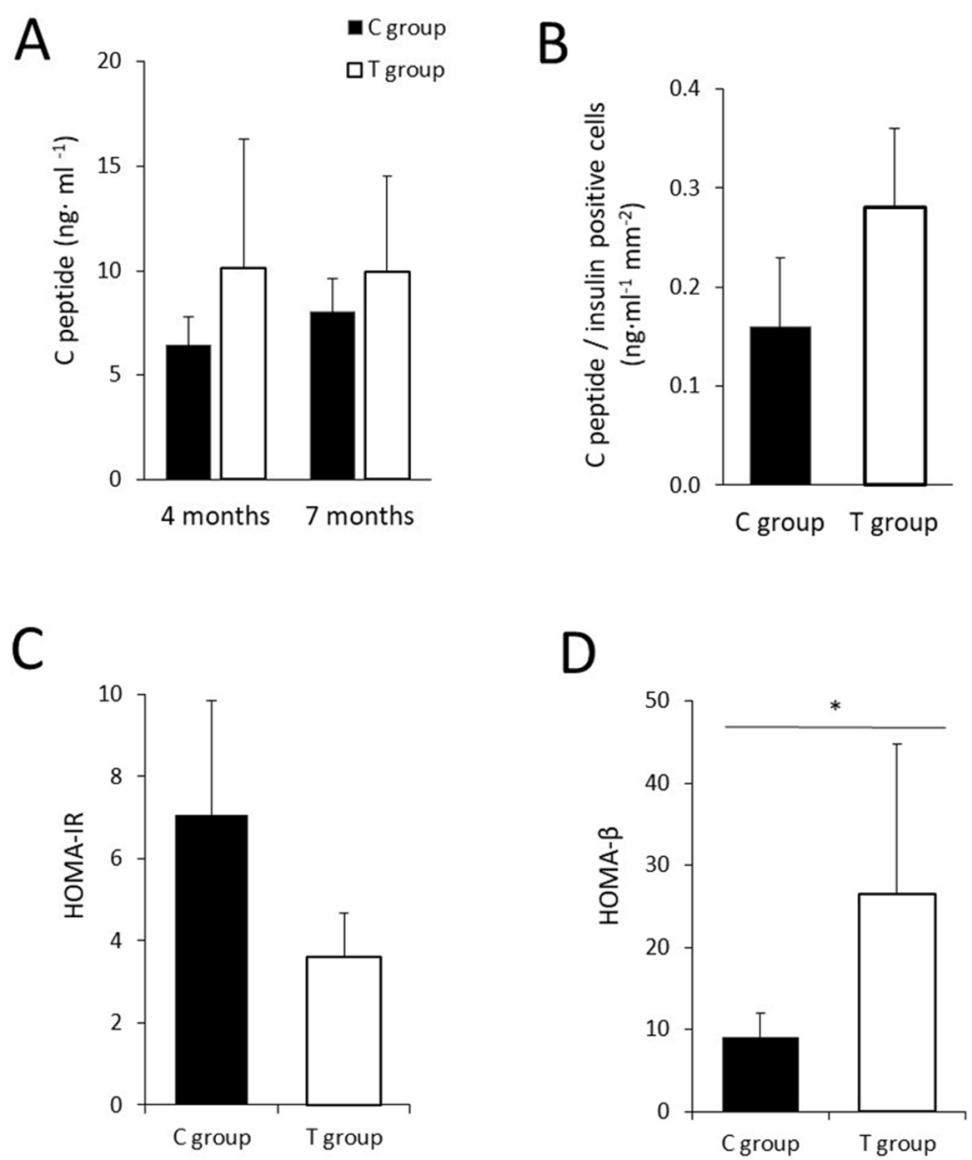

Figure 4. Pancreatic function. (A) No statistical significant differences were found between serum C-peptide levels in $\mathrm{C}$ and $\mathrm{T}$ groups at four months $\left(6.2 \pm 1.7\right.$ versus $9.1 \pm 6.6 \mathrm{ng} \mathrm{mL}^{-1}$, respectively; $p=0.234)$ and seven months ( $7.6 \pm 1.7$ versus $8.5 \pm 4.6 \mathrm{ng} \mathrm{mL}^{-1}$, respectively; $\left.p=0.792\right)$. (B) When values of C-peptide/insulin positive cells were determined, a higher value was found in $\mathrm{T}$ group although statistical differences were not found $\left(0.2 \pm 0.1\right.$ versus $0.3 \pm 0.1 \mathrm{ng} \mathrm{mL}^{-1} \mathrm{~mm}^{-2}$ in $C$ and $\mathrm{T}$ groups, respectively, $p=0.114$ ). The homeostatic model assessment (HOMA)-IR (C) did not reflect differences among groups, however statistical significant differences were found in HOMA- $\beta$ (D), between T and C groups (26.6 \pm 18.2 versus $9.0 \pm 2.9$, respectively; $p=0.029)$; $(n=4$ in C group and $n=4$ in T group). Results are expressed as mean \pm SD. ${ }^{*} p<0.05$. 
With respect to the homeostatic model assessment (HOMA) no significant differences were observed in the HOMA-IR $(p=0.114)$. However, statistical significant differences were found in the HOMA- $\beta(p=0.029)$, remarking a better $\beta$-cell functionality in the group supplemented with the FFP (Figure $4 \mathrm{C}, \mathrm{D})$.

\subsection{FFP Supplementation Induces a Decrease in Intestinal Glucose Uptake}

To test whether the hypoglycemic actions of FFP supplementation could be related to a decrease in intestinal sugar uptake, we measured the ex vivo $\alpha$-MG uptake in intestinal everted rings from animals after treatment. A significant decrease in intestinal $\alpha$-MG uptake was observed in animals receiving FFP compared to the control group $(p=0.029)$ (Figure 5).

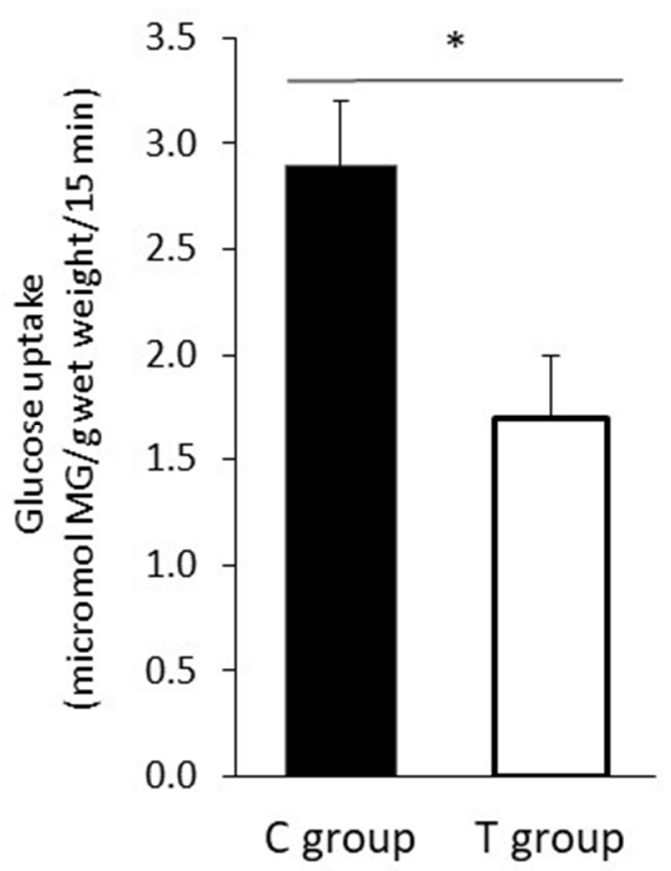

Figure 5. Intestinal glucose uptake. When intestinal glucose transport was determined, it was found that animals administered the FFP ( $\mathrm{T}$ group) exhibited statistically significant lower marked glucose uptake compared to animals in $C$ group $\left(1.7 \pm 0.7\right.$ versus $2.9 \pm 0.6$ micromol MG g wet weight ${ }^{-1} 15 \mathrm{~min}^{-1}$; $p=0.029) ;\left(n=4\right.$ in C group and $n=5$ in T group). Results are expressed as mean \pm SD. ${ }^{*} p<0.05$.

\subsection{The Administration of the FFP Altered the Composition of Faecal Microbiota}

At phylum level, Firmicutes, Proteobacteria, Bacteroidetes, and Actinobacteria were the more predominant phyla present in the fecal samples of both groups (Figure 6A). After FFP supplementation, the percentage of Firmicutes was statistical significantly higher in the $\mathrm{C}$ group than in the $\mathrm{T}$ group $(p=0.017)$ and no statistical differences were found between groups in the Bacteroidetes phylum (Figure 6B), probably due to the variability observed. The ratio of Firmicutes to Bacteroidetes is a widely used indicator of the microbial composition, however in our study its value was comparable in both groups (1.23 versus 1.08 in C group and T group, respectively). At the family level the more abundant taxa were Lactobacillaceae (4.1\%), Enterobacteriaceae (3.6\%), Porphyromonadaceae (3.6\%), Lachnospiraceae $(3.5 \%)$, and Ruminococcaceae (3.4\%) (Figure S4). Statistically significant differences were only observed in Streptococcaceae $(p=0.046)$ and Sutterellaceae $(p=0.046)$ families. The Streptococcaceae family was higher in C group while the Sutterellaceae was higher in T group (Figure 6C). 
A
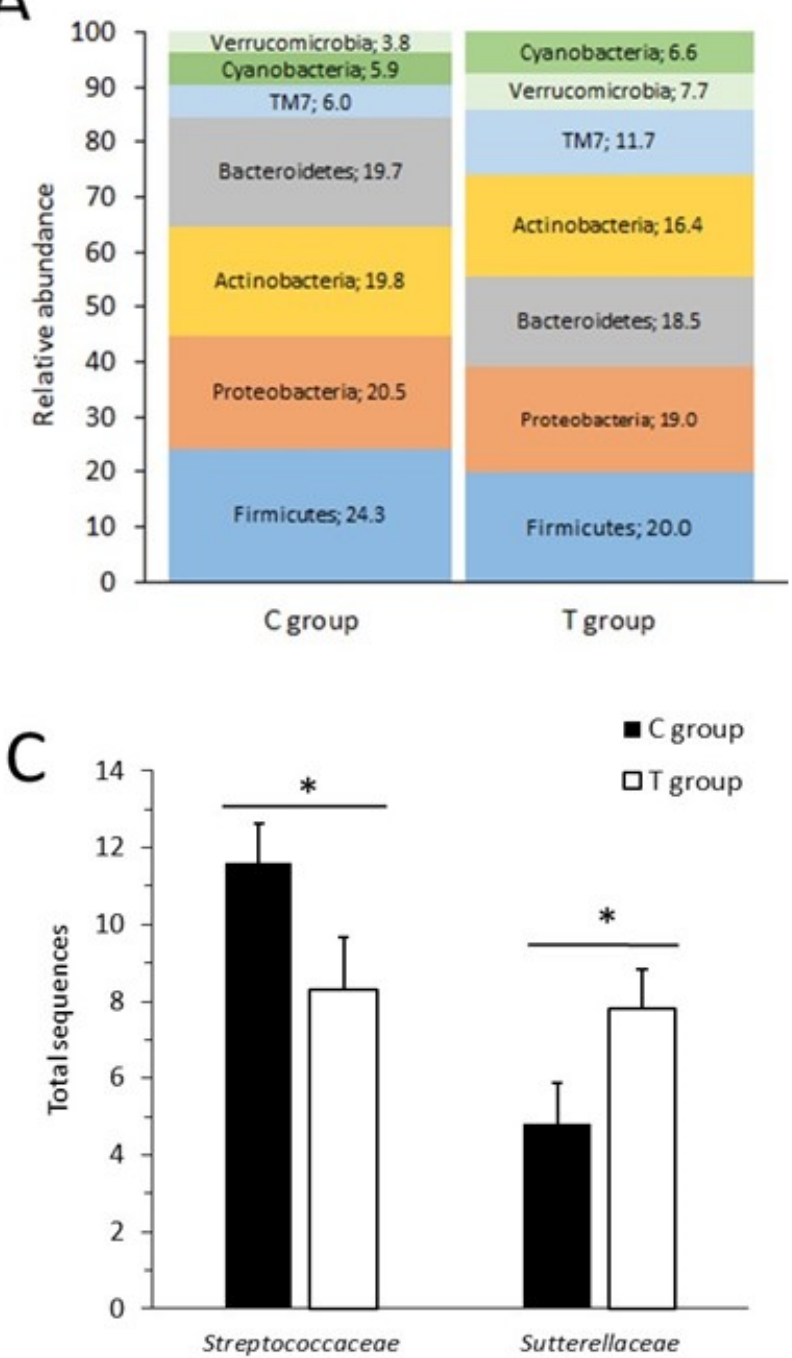
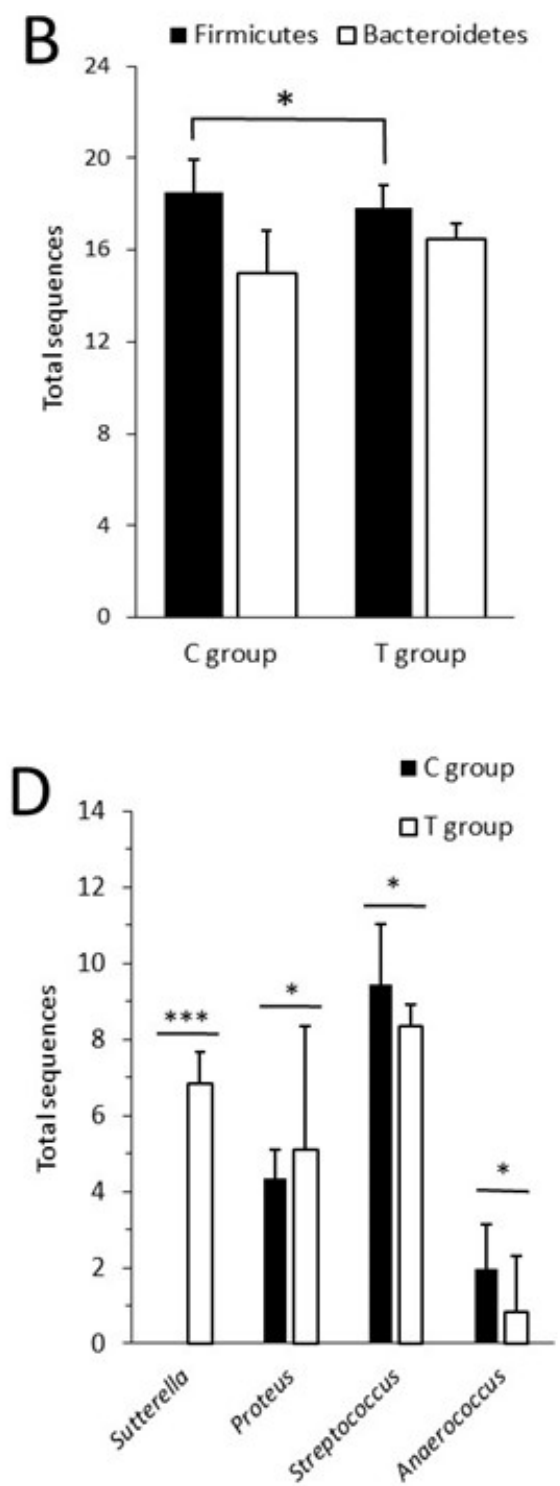

Figure 6. Fecal microbiota composition at phylum, family and genus level. (A) Relative abundance of phyla present in fecal samples in $\mathrm{C}$ and T groups. (B) Contributions of Firmicutes and Bacteroidetes. The abundance of Firmicutes was statistically significant higher in the $\mathrm{C}$ group than in the $\mathrm{T}$ group ( $p=0.017)$ however no statistically significant differences were found in Firmicutes to Bacteroidetes ratio; ( $n=3$ in C group and $n=3$ in T group). (C) Fecal microbiota composition at family level. Streptococcaceae contribution was significantly higher in the control rats than in the treated ones while Sutterellaceae was enriched in the treated animals; ( $n=3$ in C group and $n=3$ in T group). (D) Widespread effect of the administration of the FFP on bacterial genera. Representation of statistically significant genera between groups at six months. Sutterella and Proteus were found enriched in the T group whereas Anaerococcus and Streptococcus were more prominent in the C group; $(n=3$ in C group and $n=3$ in T group). ${ }^{*} p<0.05,{ }^{* * *} p<0.01$.

The study of the total abundance of the genera revealed that the dominant bacteria genera were Lactobacillus (2.85\%), Clostridium (2.26\%), Bifidobacterium (2.26\%), Barnesiella (2.22\%), and Bacteroides (2.17\%). From all 123 different identified genera, four and 19 were found exclusively in C or $\mathrm{T}$ groups, respectively (Tables S5 and S6). At genus level, the supplementation with the FFP enriched the abundance of Sutterella and Proteus, which were found more prominent in the T group $(p<0.001$ and $p=0.032$, respectively), while Anaerococcus and Streptococcus were more copious in control animals ( $p=0.032$ for both genera) (Figure 6D). 
A sum of 433 different bacterial species were identified in all the samples, of which 26 and 100 were exclusive of the C and T group, respectively (Tables S5 and S6). A mutual core of 307 shared species was found in the two groups and among them 30 bacterial species significantly differed in the number of total sequences (Figure 7).

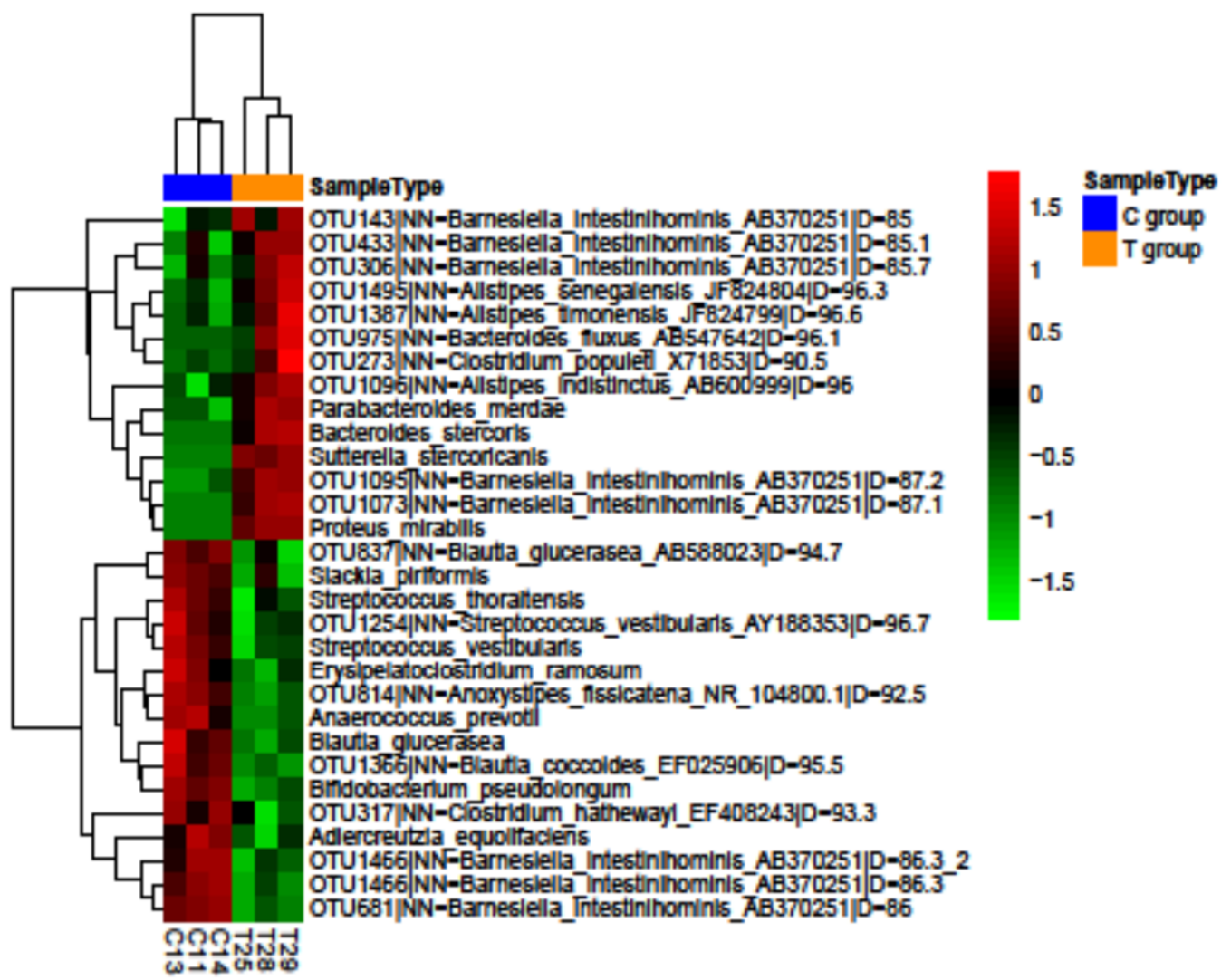

Figure 7. Hierarchical clustering. Hierarchical clustering of differentially abundant species $(p<0.05)$ in C group and T group at six months; ( $n=3$ in C group and $n=3$ in T group).

Diversity of the fecal microbiota were also analyzed. Alpha diversity indexes of bacterial community in ZDF rats are presented in Table 1 . The alpha diversity was greater in $T$ group than in $C$ group, as samples in control group are perceived to have lower value in four of the five analyzed indexes. This may suggest that the administration of the FFP lead to an enrichment of the microbial diversity.

Table 1. Ecological indexes of Alpha diversity.

\begin{tabular}{cccccc}
\hline Sample & ACE & Chao1 & Observed Species & Shannon & Simpson \\
\cline { 1 - 5 } C group & $2235.43 \pm 314.85$ & $2280.57 \pm 322.74$ & $1900.00 \pm 298.08$ & $4.99 \pm 0.72$ & $0.98 \pm 0.01$ \\
\cline { 1 - 5 } T group & $2837.85 \pm 668.01$ & $2868.51 \pm 646.40$ & $2510.67 \pm 655.89$ & $5.04 \pm 0.76$ & $0.98 \pm 0.02$ \\
\hline \multicolumn{7}{c}{ Values expressed as mean \pm SD. }
\end{tabular}

A non-metric multidimensional scaling analysis (NMDS) was performed in order to analyze the observed variability. The NMDS plot (Figure 8) showed that the distances between samples from the $C$ group are shorter than those between samples in the $T$ group. This means that $C$ group presents a higher microbial homogeneity and so animals were more similar to each other than the treated animals. 


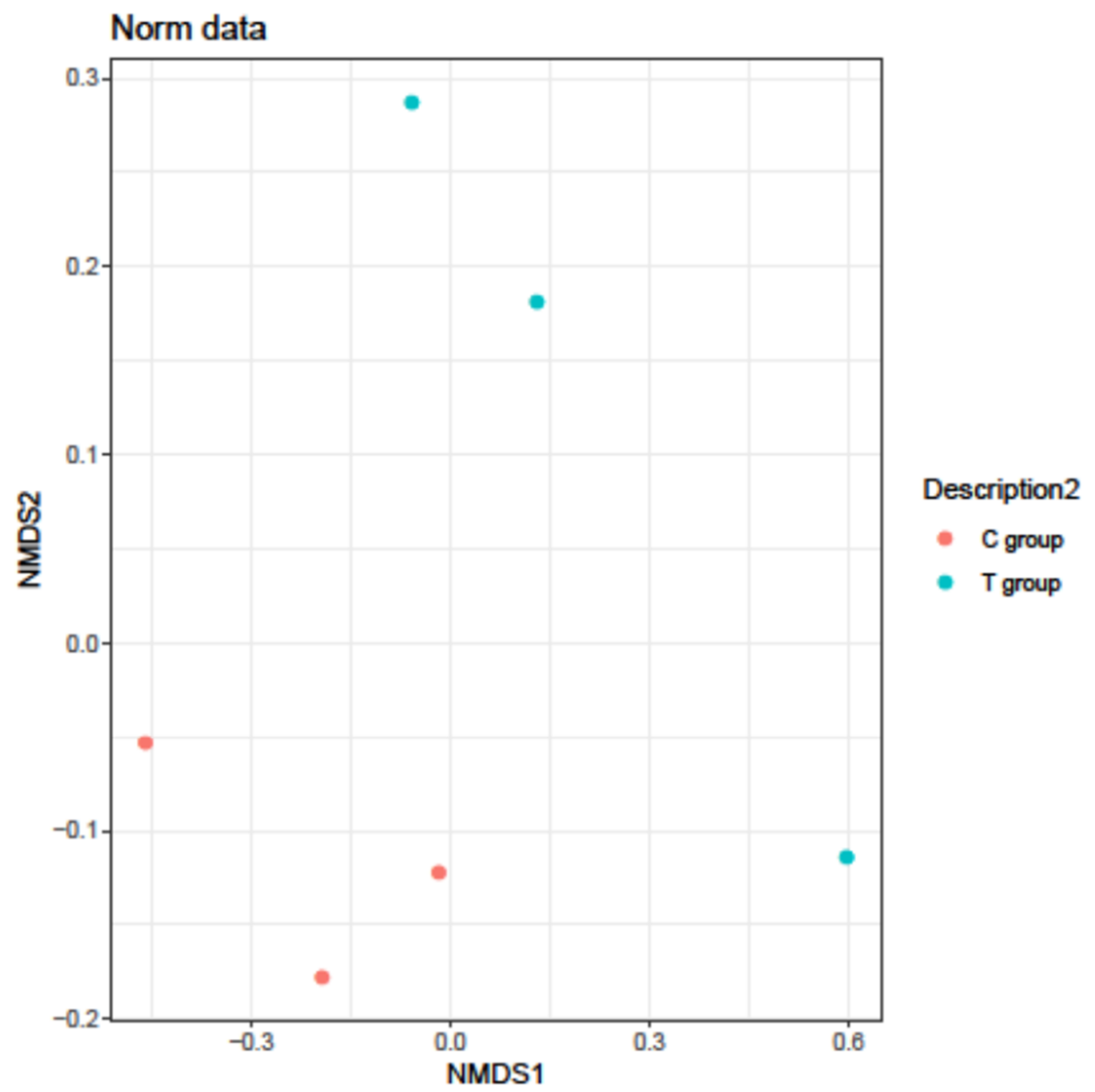

Figure 8. Non-metric multidimensional scaling analysis (NMDS). Representation of samples from C group and T group at six months; ( $n=3$ in C group and $n=3$ in T group).

\section{Discussion}

Recent findings regarding T2D have led to new valuable knowledge on diabetic etiology and risk factors. Specifically, considerable interest exists in the role of the GM in the development and progression of diabetes. Several publications showed that diabetic individuals present a characteristic intestinal microbial community. This distinctive GM includes altered abundance of some bacteria taxa, for instance increased presence of Lactobacillus genera and opportunistic pathogens, along with differences in metabolic functionality, such as enhanced sulphate reduction and oxidative stress resistance [12]. Moreover, there is evidence that the GM influences the progression of the diabetes and its related complications [40] and its restoration resulted in clinical improvements according to experimental and clinical data. In particular, diet appears to play a key role and nutritional interventions have received attention for their ability to normalize the intestinal microbiota and thus improve health status [41].

In the present study a non-dairy fermented product was tested for its effectiveness in relieving the diabetic phenotype in the ZDF model. Among our experimental data, the markedly decreased glucose absorption in the treated group is probably the most striking result to emerge. Although extreme caution must be taken when extrapolating the results from ex vivo experiments, our result suggests that the total glucose which reach the systemic circulation was strongly attenuated with the FFP supplementation. This would support the lower BFG and GTT values observed in the T group. 
We hypothesized that the FFP is able to improve the intestinal integrity and to decrease the load of glucose which reach the systemic environment, as suggested by previous authors [42]. A body of evidence has indicated an altered gut environment in diabetic people which includes a compromised tight-junction structure [43], a disrupted gut barrier [40], and impaired glucose transporters in the gut [42]. Taking it all into consideration, any approach that pursue to restore the gut health would eventually induce beneficial changes in the host.

A slightly higher value of $C$-peptide was also noticed in the supplemented group. The concentration of C-peptide represents an indirect estimation of $\beta$-cell activity as it leaks from proinsulin cleavage [44]. On the other hand, although the number of insulin positive cells present in the pancreas of the $C$ group was greater, we observed that $\beta$-cells were more efficient in the T group because a higher endogenous insulin production per $\beta$-cell was measured. Such findings indicate that the $\beta$-cell mass was best preserved in the T group. This is in good agreement with the HOMA- $\beta$ score, and all together suggests a healthier pancreatic function in the $\mathrm{T}$ group. We believe that the treatment indirectly protected from organs dysfunction through a systemic effect, which together with the normalized values of glycemia observed in the T group in both BFG and GTT determinations could be responsible for the better pancreatic activity reported in this group.

Both the restoration of the glucose homeostasis and the protection of the pancreatic activity could be responsible for the improved wellness of the treated ZDF rats. A correct glucose metabolism can lessen alterations in cardio-metabolic parameters and result in a healthier lipid profile. Based on the physiological process of the T2D, also mimicked in the ZDF rat model, a deterioration in the lipid profile would be predicted along with the diabetes progression in both groups. However, our data reflected better values of TG, transaminases, and AI index in the T group. In this context, the observed results may suggest that the FFP helped to some extent to prevent diabetes-associated secondary alterations. Most of the analyzed parameters in the current research showed a tendency of a healthier status in the T group, and this trend was strongly manifested along the study by the greater survival observed in the supplemented group. As a result, the FFP-treated animals showed a prolonged survival in comparison with the control animals. It is also worth noting that the only animal that died in the group treated with FFP did so in week 28, while the first animal that did it in the control group was in week 15.

In addition to the mechanisms outlined above, another feasible explanation for the better glucose homeostasis in the T group is that the GM functional properties were affected by the FFP, and the ability to metabolize glucose was increased in some bacteria groups. Gut dysbiosis has been described in relation to glucose dyshomeostasis and emerging experimental and clinical evidence suggests that GM activity is modified in T2D $[12,40,45,46]$. Because of the key endocrine function exerted by the GM [47], restoring its metabolic function is a valuable approach which proved to be successful in provoking significative changes [14]. In the metagenomic analysis of the fecal microbiome obtained from the ZDF rats performed in the present study we could identify some differences among groups' samples and some results did not confirm previous research on the topic. For instance, we did not find significant differences in Firmicutes to Bacteroidetes ratio. It is a relevant but controversial microbial marker. A reduced Bacteroidetes contribution or increased Firmicutes to Bacteroidetes ratio have been reported in obesity [48], and this parameter was found to be partially restored following weight loss [49] or prebiotic treatment [50]. On the contrary, other researchers have reported a significantly higher Firmicutes to Bacteroidetes ratio in lean than in overweighed or obese individuals [51]. In line with this observation, our results indicate a significant higher contribution of Firmicutes in the T group; however, our data did not reveal significant differences in the aforementioned ratio. Unlike other investigations carried out on the topic, we did not find a significant increase in Bifidobacterium levels. Based on the characteristics of the FFP, whose composition includes a high level of fermentable carbohydrates [52], a bifidogenic effect was expected in the T group due to the metabolites obtained during the fermentation process of FFP. This change is desired because this bacteria genera is a health 
marker [53]. However, our results indicate that the analyzed product or the experimental design could not induce a bifidogenic effect.

At the family level, Streptococcaceae was found significantly enriched in the control group, which matches with a previous type 1 diabetes (T1D) human trial [54]. On the contrary, Sutterellaceae family, which includes commensal species found in healthy human and animals [55], was more predominant in the treated group. At the genus level a significant enrichment was observed in Sutterella in the treated group. This finding does not corroborate previous results from earlier case-control studies in prediabetic subjects [56], experimental studies on type 1 diabetic animal models [57] and reports in other pathological conditions such as autism [58] and atopic dermatitis [59]. However, our finding matches to a previous investigation that associated barley consumption, a main component in FFP formulation, with an elevated abundance of Sutterella in the human GM [60]. Proteus genus was also enriched in the supplemented rats. Although there is no evidence about the function of this genus in diabetes or obesity, some authors suggest its role in some pathological conditions [61,62]. In fact, one specie, P. mirabilis, was negatively correlated to health improvements $[63,64]$, what suggests that a low abundance should be wanted. In contrast, our metagenomic analysis revealed that P. mirabilis was significantly enriched in the treated group. What is more, it was completely absent in control animal samples. We have no explanation for this striking result. Regarding the C group, Anaerococcus and Streptococcus genera were found more prominent. A previous report confirmed a lower relative abundance of the former genera in diabetic compared to healthy adults [65], contrary to our results. The latter genera, however, presented a greater relative abundance in prediabetic [56], type 2 diabetic [66], and type 1 diabetic individuals [67] compared to their healthy controls, what matches to our findings.

Among the 30 bacteria species statistically different between groups, eight Barnesiella spp. were identified and five of them were greater in the treated group. A previous experimental study reported an increased abundance of this genus in obese mice supplemented with prebiotics which experienced a better glucose tolerance and important metabolic improvements [68]. We also discovered that two Blautia spp. (B. coccoides and B. glucerasea) were more prominent in the control animals. This genus belongs to the family Lachnospiraceae and includes butyrate producing bacteria (BPB), a group which has been attributed many beneficial effects [69]. It was reported some positive correlations between Blautia spp. and microbial products such as long-chain triglycerides [70] and short chain fatty acids (SCFAs) [71], and parameters like BFG, insulin level, HOMA-IR, and weight loss [56,72]. A decreased abundance of Blautia coccoides/Eubacterium rectale was found in T1D children and was linked to intestinal disintegrity [73], while a randomized crossover study in healthy adults reported a reduced abundance of Blautia genus after prebiotic supplementation [74]. These results appear inconclusive. Our data also showed three Alistipes spp. enriched in the group supplemented with the fermented product. On the contrary, previous works reported its enrichment in T1D [67] and T2D individuals [12]. In the same way, our data revealed a lower abundance of two Streptococcus spp. (S. thoraltensis and S. vestibularis) in the group which exhibited a better glucose control (T group) and refute previous research [66].

The relative abundance of Anaerococcus, genus which includes many bacteria species which produce butyrate in experimental conditions [75], was significantly enriched in the treated group. Metagenome-wide association studies (MGWAS) on T2D humans revealed a compromised gut health with an abnormal abundance of BPB, thus an enrichment of the aforementioned bacteria group could, hypothetically, have led to improvements in the health status of the T group [12,46]. Regrettably, this study did not confirm previous research and the treatment with the FFP did not induce changes in well described BPB spp such as Akkermasia muciniphila. A. muciniphila is a mucus producer belonging to the Verrucomicrobiae family which has been hypothesized to protect against T2D and obesity in animal studies $[69,76]$. Increased levels of A. muciniphila were correlated to improvements in health parameters in healthy $[77,78]$ and HD-fed mice [76], and previous works in healthy mice showed that dietary manipulation such as supplementation with prebiotics could increase the abundance of intestinal 
A. muciniphila [79]. It seems that the nutritional properties of the FFP and/or the study design did not allow for a greater presence of $A$. muciniphila in the GM.

Regardless microbial populations, microbial metabolites are also of great importance and could be partly responsible for the improved glucose control and gut health found in the T group. Considerable interest exists in SCFAs such as acetate, propionate, and butyrate. They are lipid molecules known to mediate in inflammation [80], gut permeability [81], energy expenditure and metabolism [51,82], and an insulin-sensitizing [83] and antidiabetic effects [84,85] have also been described for them. Taking it into consideration, the promotion of their physiological levels can lead to an improved overall health, and may partly explain the favorable phenotype reported in the treated animals.

Since the FFP is rich in factors associated to a reduced food ingestion, such as fiber, microbial metabolites, and probiotic LABs [86-88], a decreased food intake was expected in the treated group. However, no considerable differences in eating behavior were observed between groups. This unexpected result is in good agreement with other previous studies with fermented dairy product in STZ-induced diabetic rats [25]. Similarly, BW was not significantly changed during the supplementation and was indeed more prominent on the $\mathrm{T}$ group. Even though these results differ from an earlier in vivo study [89] and a crossover trial in prediabetic humans [18] that found a protection from weight gain for fermented products, they are consistent with previous finding in ZDF rats and other animal models of T2D [90,91]. Although no anti-obesity effect was observed for the FFP, it remains unknown whether it has some effect on body gain. May studies on another obesity rodent's model elucidate the impact of FFP on body mass regulation such as the ob/ob mouse model. The unexpected dramatic reduction in $\mathrm{BW}$ in the $\mathrm{C}$ group could be consequence of an acute failure of the pancreatic function. The decline in C-peptide levels in control rats suggest a low serum insulin level which, along with a compromised insulin signaling would promote lipolysis and favor fat mobilization from the tissue [92,93]. In much the same way, a FFP-mediated increase of SCFA levels in the T group, microbial metabolites known to downregulate lipolysis [94-96], could have prevented from the loss of weight in the treated ZDF rats. A previous report on Monascus fermented rice concluded that the differences in weight loss between control versus treated animals could be caused by a depletion in the lean mass in the former as results of diabetic complications [90]. In the present research, however, the nuclear magnetic resonance revealed the absence of discrepancies in body composition after FFP supplementation. It differs from previous results on fermented food in controlled intervention studies [18,97] and animals models [98] which evidenced a significant decrease in body weight and fat depots. Nevertheless, the absence of significant changes in body composition did not abstain from improvements in glucose homeostasis, what matches well with previous findings in murine models of obesity $[99,100]$.

With reference to the microbial diversity, the results of the analysis strongly indicate that the FFP supplementation led to a greater diversity in the microbial communities which inhabit the gut environment of the ZDF rats. Another plausible explanation may be that the FFP abstained from the loss of diversity which consorts some clinical disorders such as obesity [48], however some controversy does exist with regards to T2D [12]. It is well-known that dietary factors, along with other external agents, have a great importance for the diversity and composition of the GM [101-103]. Previous works already studied changes in alpha-diversity with the consumption of diverse functional compounds. For instance, a meta-analysis compared different prebiotic treatments, and their efficacy in increasing bacteria richness was found to be dependent on the fiber used and the diversity index calculated. The authors concluded that fiber interventions did not increase alpha-diversity [104]. They however suspected that a longer exposition would reveal some differences, what is in good agreement with our findings. Further, other authors reached the conclusion that the bigger the diversity of the GM, the bigger its resilience against external challenges [13]. This might consequently provide a healthier phenotype since a low bacteria richness was found to be present in illnesses and pathological conditions $[103,105]$ and may this stability explain the better status reported for the treated group in our study. However, a compromised gut richness is not always present on T2D according to findings from a MGWAS with diabetic individuals [12] and bacterial diversity should not be the only focal 
point. Some authors call for a deeper approach and suggest that GM metabolic functionality, and not only its phylogenetic composition, could be an interesting target for future research and shed light on this point [106]. Then a more comprehensive approach is recommended.

This is not the first study reporting a hypoglycemic effect of probiotic bacteria or fermented products in animal models, however, there is a critical need for well-designed, controlled studies in humans to provide solid evidence of the suitability of fermented food for T2D management or prevention. Although the evidence from controlled trials in humans is limited and arises from small sample sizes $[18,107]$, the number of work assessing the antidiabetic effects of fermented products in humans continues to grow $[98,108]$. Different fermented food products were investigated for their ability to exert antidiabetic effects and a wide variety of outcomes and levels of scientific evidence were reported [27]. On account of the fact that the study sample was small, and it was a preliminary attempt to test the FFP on an in vivo model, we strongly believe that a bigger sample size would have evidence more differences in the analyzed parameters. Nevertheless, previous supplementation with live bacteria in a different T2D murine model also failed to find significant differences in some metabolic markers and it did not abstain from relevant beneficial effects in pancreatic function and glucose homeostasis [109]. Nonetheless, the present research presents a valuable characteristic regarding its experimental design. In contrast to some reports in the literature in which the supplementation lasted for a few weeks $[18,90,97]$, we supplemented the rats for a longer time period (31 weeks). This prolonged exposition allowed us the examination of long-term responses.

Notwithstanding, as discussed above, we strongly believe that more work is needed to further understand how FFP works and thereafter, validate its potential effectiveness in diabetic patients. A future double-blind, placebo-controlled study with T2D individuals is being considered and would provide insight into the potential antidiabetic properties of FFP in humans. As not all the strains belonging to the same specie shares exactly the same beneficial effect [28,29], probably because of tiny differences in their physical and chemical properties [110], a full and comprehensive identification of the multi-species consortia of microorganisms presents in FFP, preferably up to strain level [111], would be of great important for it further characterization.

\section{Conclusions}

In summary, we demonstrated that the FFP was favorable on glucose metabolism and contributed to health maintenance, abstained from T2D harmful effects and improved overall life expectancy. Our study is in line with previous studies showing that modulation of GM can confer health benefits on T2D and OB. However, it is a fundamental issue to determine which component(s) present in the FFP is/are responsible for the observed beneficial effects. Research into solving this dilemma is already underway and we hope we could elucidate this issue. Future works on the topic would clearly be worth pursuing. Importantly, the undeniable disparities between experimental models and humans challenge the extrapolation of data from in vivo studies to humans, and a large well-controlled trial with an appropriate study design and statistical methods is needed to provide firm evidence of FFP's antidiabetic properties.

These findings spotlight once again the role of microorganisms and gut function on the diabetic pathology and indicate that novel fermented products could be a powerful tool to protect against metabolic alterations. Nevertheless, very few publications are available in the literature that address the application of fermented products in diabetic humans and discordance within conclusions makes difficult the elucidation of reliable markers. Our results open the possibility to explore the effectivity of innovative fermented food products in $\mathrm{T} 2 \mathrm{D}, \mathrm{OB}$, and other non-communicable diseases in a near future.

Supplementary Materials: The following are available online at http://www.mdpi.com/2072-6643/11/10/2530/s1, Figure S1: Image of the FFP, Figure S2: Experimental design, Figure S3: Body composition at the time of sacrifice measured by nuclear magnetic resonance (NMR), Figure S4: Relative abundance of fecal microbiota at the family level, Table S1: Culturable and viable counts determined in the FFP, Table S2: Composition of FFP and ENVIGO 
TD.06416 hypercaloric diet, Table S3: Body fat weight for rats in C and T groups, Table S4: Follow-up of lipid profile in ZDF rats, Table S5: List of bacteria species and OTUs which were identified exclusively in the C group, Table S6: List of bacteria species and OTUs which were identified exclusively in the T group.

Author Contributions: Conceptualization M.B. and M.A.; performing the experiment, M.C.-O., M.O., N.S. and M.A.; investigation and formal analysis, M.C.-O. and M.A.; metagenomics analysis, E.G.; writing-original draft preparation, M.C.-O., M.B. and M.A.; writing-review and editing, M.J.M.-A., I.J.E., M.B. and M.A.; supervision, P.T. and J.V.D.; funding acquisition, I.J.E. and M.B.

Funding: This research was funded by grant from Advanced Innovation \& Technology Corporation (ADItech Corp, Department of Economic Development, Navarre Government) [Reference: PT022 SIMDIACOL]. Miriam Cabello-Olmo was granted by the Industrial PhD program (Navarre Government) [Reference: 001114082016000011].

Conflicts of Interest: The authors declare no conflict of interest.

\section{References}

1. American Diabetes Association. Diagnosis and classification of diabetes mellitus. Diabetes Care 2014, 37, S81-S90. [CrossRef] [PubMed]

2. World Health Organization Global Status Report on Noncommunicable Diseases; WHO: Geneva, Switzerland, 2014.

3. Brunkwall, L.; Orho-Melander, M. The gut microbiome as a target for prevention and treatment of hyperglycaemia in type 2 diabetes: From current human evidence to future possibilities. Diabetologia 2017, 60, 943-951. [CrossRef] [PubMed]

4. Velmurugan, G.; Ramprasath, T.; Gilles, M.; Swaminathan, K.; Ramasamy, S. Gut Microbiota, Endocrine-Disrupting Chemicals, and the Diabetes Epidemic. Trends Endocrinol. Metab. 2017, 28, 612-625. [CrossRef] [PubMed]

5. Ley, R.E.; Peterson, D.A.; Gordon, J.I. Ecological and Evolutionary Forces Shaping Microbial Diversity in the Human Intestine. Cell 2006, 124, 837-848. [CrossRef] [PubMed]

6. Villanueva-Millán, M.J.; Pérez-Matute, P.; Oteo, J.A. Gut microbiota: A key player in health and disease. A review focused on obesity. J. Physiol. Biochem. 2015, 71, 509-525. [CrossRef] [PubMed]

7. Blandino, G.; Inturri, R.; Lazzara, F.; Di Rosa, M.; Malaguarnera, L. Impact of gut microbiota on diabetes mellitus. Diabetes Metab. 2016, 42, 303-315. [CrossRef] [PubMed]

8. Quigley, E.M.M. Gut Bacteria in Health and Disease. Gastroenterol. Hepatol. 2013, 9, 560-569.

9. Hersoug, L.-G.; Møller, P.; Loft, S. Gut microbiota-derived lipopolysaccharide uptake and trafficking to adipose tissue: Implications for inflammation and obesity. Obes. Rev. 2016, 17, 297-312. [CrossRef]

10. Cani, P.D.; Delzenne, N.M. Interplay between obesity and associated metabolic disorders: New insights into the gut microbiota. Curr. Opin. Pharmacol. 2009, 9, 737-743. [CrossRef]

11. Kootte, R.S.; Vrieze, A.; Holleman, F.; Dallinga-Thie, G.M.; Zoetendal, E.G.; de Vos, W.M.; Groen, A.K.; Hoekstra, J.B.L.; Stroes, E.S.; Nieuwdorp, M. The therapeutic potential of manipulating gut microbiota in obesity and type 2 diabetes mellitus. Diabetes Obes. Metab. 2012, 14, 112-120. [CrossRef]

12. Qin, J.; Li, Y.; Cai, Z.; Li, S.; Zhu, J.; Zhang, F.; Liang, S.; Zhang, W.; Guan, Y.; Shen, D.; et al. A metagenome-wide association study of gut microbiota in type 2 diabetes. Nature 2012, 490, 55-60. [CrossRef] [PubMed]

13. Salonen, A.; Lahti, L.; Salojärvi, J.; Holtrop, G.; Korpela, K.; Duncan, S.H.; Date, P.; Farquharson, F.; Johnstone, A.M.; Lobley, G.E.; et al. Impact of diet and individual variation on intestinal microbiota composition and fermentation products in obese men. ISME J. 2014, 8, 2218-2230. [CrossRef] [PubMed]

14. David, L.A.; Maurice, C.F.; Carmody, R.N.; Gootenberg, D.B.; Button, J.E.; Wolfe, B.E.; Ling, A.V.; Devlin, A.S.; Varma, Y.; Fischbach, M.A.; et al. Diet rapidly and reproducibly alters the human gut microbiome. Nature 2014, 505, 559-563. [CrossRef] [PubMed]

15. FAO/WHO. Guidelines for the Evaluation of Probiotics in Food; FAO: Rome, Italy; WHO: Geneva, Switzerland, 2002.

16. Gibson, G.R.; Hutkins, R.; Sanders, M.E.; Prescott, S.L.; Reimer, R.A.; Salminen, S.J.; Scott, K.; Stanton, C.; Swanson, K.S.; Cani, P.D.; et al. Expert consensus document: The International Scientific Association for Probiotics and Prebiotics (ISAPP) consensus statement on the definition and scope of prebiotics. Nat. Rev. Gastroenterol. Hepatol. 2017, 14, 491-502. [CrossRef] [PubMed]

17. Tian, P.; Li, B.; He, C.; Hou, A.; Meng, X.; Song, W.; Tian, S.; Li, K.; Shan, Y. Antidiabetic (type 2) effects of Lactobacillus G15 and Q14 in rats through regulation of intestinal permeability and microbiota. Food Funct. 2016, 7, 3789-3797. [CrossRef] 
18. An, S.-Y.; Lee, M.S.; Jeon, J.Y.; Ha, E.S.; Kim, T.H.; Yoon, J.Y.; Ok, C.-O.; Lee, H.-K.; Hwang, W.-S.; Choe, S.J.; et al. Beneficial Effects of Fresh and Fermented Kimchi in Prediabetic Individuals. Ann. Nutr. Metab. 2013, 63, 111-119. [CrossRef]

19. Sato, J.; Kanazawa, A.; Azuma, K.; Ikeda, F.; Goto, H.; Komiya, K.; Kanno, R.; Tamura, Y.; Asahara, T.; Takahashi, T.; et al. Probiotic reduces bacterial translocation in type 2 diabetes mellitus: A randomised controlled study. Sci. Rep. 2017, 7, 12115. [CrossRef]

20. Galgano, F.; Condelli, N.; Caruso, M.C.; Maria Antonietta Colangelo, F.F. Probiotics and Prebiotics in Fruits and Vegetables: Technological and Sensory Aspects. In Beneficial Microbes in Fermented and Functional Foods; Rai, V.R., Bai, J.A., Eds.; CRC PRESS: Boca Raton, FL, USA, 2015; Volume 10, pp. 189-206.

21. Panghal, A.; Janghu, S.; Virkar, K.; Gat, Y.; Kumar, V.; Chhikara, N. Potential non-dairy probiotic products -A healthy approach. Food Biosci. 2018, 21, 80-89. [CrossRef]

22. Wang, B.; Charukeshi Chandrasekera, P.; JPippin, J. Leptin- and Leptin Receptor-Deficient Rodent Models: Relevance for Human Type 2 Diabetes. Curr. Diabetes Rev. 2014, 10, 131-145. [CrossRef]

23. Finegood, D.T.; McArthur, M.D.; Kojwang, D.; Thomas, M.J.; Topp, B.G.; Leonard, T.; Buckingham, R.E. $\beta$-Cell Mass Dynamics in Zucker Diabetic Fatty Rats. Diabetes 2001, 50, 1021-1029. [CrossRef] [PubMed]

24. Tomaro-Duchesneau, C.; Saha, S.; Malhotra, M.; Jones, M.L.; Labbé, A.; Rodes, L.; Kahouli, I.; Prakash, S. Effect of orally administered L. fermentum NCIMB 5221 on markers of metabolic syndrome: An in vivo analysis using ZDF rats. Appl. Microbiol. Biotechnol. 2014, 98, 115-126. [CrossRef] [PubMed]

25. Yadav, H.; Jain, S.; Sinha, P.R. Oral administration of dahi containing probiotic Lactobacillus acidophilus and Lactobacillus casei delayed the progression of streptozotocin-induced diabetes in rats. J. Dairy Res. 2008, 75, 189-195. [CrossRef] [PubMed]

26. Li, X.; Zhao, J.; Wang, G.; Zhang, H.; Chen, W. Correction: Lactobacillus casei CCFM419 attenuates type 2 diabetes via a gut microbiota dependent mechanism. Food Funct. 2017, 8, 3814.

27. Gille, D.; Schmid, A.; Walther, B.; Vergères, G. Fermented Food and Non-Communicable Chronic Diseases: A Review. Nutrients 2018, 10, 448. [CrossRef]

28. Miniello, V.L.; Colasanto, A.; Cristofori, F.; Diaferio, L.; Ficele, L.; Lieggi, M.S.; Santoiemma, V.; Francavilla, R. Gut microbiota biomodulators, when the stork comes by the scalpel. Clin. Chim. Acta 2015, 451, 88-96. [CrossRef]

29. Hill, C.; Guarner, F.; Reid, G.; Gibson, G.R.; Merenstein, D.J.; Pot, B.; Morelli, L.; Canani, R.B.; Flint, H.J.; Salminen, S.; et al. Expert consensus document: The international scientific association for probiotics and prebiotics consensus statement on the scope and appropriate use of the term probiotic. Nat. Rev. Gastroenterol. Hepatol. 2014, 11, 506-514. [CrossRef]

30. López-Yoldi, M.; Castilla-Madrigal, R.; Lostao, M.P.; Barber, A.; Prieto, J.; Martínez, J.A.; Bustos, M.; Moreno-Aliaga, M.J. Cardiotrophin-1 decreases intestinal sugar uptake in mice and in Caco-2 cells. Acta Physiol. 2016, 217, 217-226. [CrossRef]

31. Dobiášová, M.; Dobiaova, M. Atherogenic index of plasma [log(triglycerides/HDL-cholesterol)]: Theoretical and practical implications. Clin. Chem. 2004, 50, 1113-1115. [CrossRef]

32. Hildebrand, F.; Tadeo, R.; Voigt, A.Y.; Bork, P.; Raes, J. LotuS: An efficient and user-friendly OTU processing pipeline. Microbiome 2014, 2, 30. [CrossRef]

33. Edgar, R.C. UPARSE: Highly accurate OTU sequences from microbial amplicon reads. Nat. Methods 2013, 10, 996-998. [CrossRef]

34. Altschul, S.F.; Gish, W.; Miller, W.; Myers, E.W.; Lipman, D.J. Basic Local Alignment Search Tool. J. Mol. Biol. 1990, 215, 403-410. [CrossRef]

35. Ritari, J.; Salojärvi, J.; Lahti, L.; De Vos, W.M. Improved taxonomic assignment of human intestinal 16S rRNA sequences by a dedicated reference database. BMC Genom. 2015, 16, 1056. [CrossRef] [PubMed]

36. Gentleman, R.C.; Carey, V.J.; Bates, D.M.; Bolstad, B.; Dettling, M.; Dudoit, S.; Ellis, B.; Gautier, L.; Ge, Y.; Gentry, J.; et al. Bioconductor: Open software development for computational biology and bioinformatics. Genome Boil. 2004, 5, R80. [CrossRef] [PubMed]

37. Ritchie, M.E.; Phipson, B.; Wu, D.; Hu, Y.; Law, C.W.; Shi, W.; Smyth, G.K. limma powers differential expression analyses for RNA-sequencing and microarray studies. Nucleic Acids Res. 2015, 43, e47. [CrossRef] [PubMed]

38. Kharroubi, A.T.; Darwish, H.M. Diabetes mellitus: The epidemic of the century. World J. Diabetes 2015, 6, 850-867. [CrossRef] [PubMed] 
39. Canivell, S.; Gomis, R. Diagnosis and classification of autoimmune diabetes mellitus. Autoimmun. Rev. 2014, 13, 403-407. [CrossRef]

40. Fukui, H. The Gut Impacts Diabetic Management Tomorrow: The Recent Messages from Intestine and Microbiota. J. Clin. Nutr. Diet. 2016, 2,1-13. [CrossRef]

41. Wen, L.; Duffy, A. Factors Influencing the Gut Microbiota, Inflammation, and Type 2 Diabetes. J. Nutr. 2017, 147, 1468S-1475S. [CrossRef]

42. Fiorentino, T.V.; Suraci, E.; Arcidiacono, G.P.; Cimellaro, A.; Mignogna, C.; Presta, I.; Andreozzi, F.; Hribal, M.L.; Perticone, F.; Donato, G.; et al. Duodenal Sodium/Glucose Cotransporter 1 Expression Under Fasting Conditions Is Associated with Postload Hyperglycemia. J. Clin. Endocrinol. Metab. 2017, 102, 3979-3989. [CrossRef]

43. Sapone, A.; De Magistris, L.; Pietzak, M.; Clemente, M.G.; Tripathi, A.; Cucca, F.; Lampis, R.; Kryszak, D.; Cartenì, M.; Generoso, M.; et al. Zonulin upregulation is associated with increased gut permeability in subjects with type 1 diabetes and their relatives. Diabetes 2006, 55, 1443-1449. [CrossRef]

44. Ludvigsson, J.; Carlsson, A.; Forsander, G.; Ivarsson, S.; Kockum, I.; Lernmark, A.; Lindblad, B.; Marcus, C.; Samuelsson, U. C-peptide in the classification of diabetes in children and adolescents. Pediatr. Diabetes 2012, 13, 45-50. [CrossRef] [PubMed]

45. Larsen, N.; Vogensen, F.K.; Berg, F.W.J.V.D.; Nielsen, D.S.; Andreasen, A.S.; Pedersen, B.K.; Abu Al-Soud, W.; Sørensen, S.J.; Hansen, L.H.; Jakobsen, M. Gut Microbiota in Human Adults with Type 2 Diabetes Differs from Non-Diabetic Adults. PLoS ONE 2010, 5, e9085. [CrossRef] [PubMed]

46. Wang, X.; Xu, X.; Xia, Y. Further analysis reveals new gut microbiome markers of type 2 diabetes mellitus. Antonie Leeuwenhoek 2017, 110, 445-453. [CrossRef] [PubMed]

47. Kasubuchi, M.; Hasegawa, S.; Hiramatsu, T.; Ichimura, A.; Kimura, I. Dietary Gut Microbial Metabolites, Short-chain Fatty Acids, and Host Metabolic Regulation. Nutrients 2015, 7, 2839-2849. [CrossRef]

48. Ley, R.E.; Bäckhed, F.; Turnbaugh, P.; Lozupone, C.A.; Knight, R.D.; Gordon, J.I. Obesity alters gut microbial ecology. Proc. Natl. Acad. Sci. USA 2005, 102, 11070-11075. [CrossRef]

49. Ley, R.E.; Turnbaugh, P.J.; Klein, S.; Gordon, J.I. Human gut microbes associated with obesity. Nature 2006, 444, 1022-1023. [CrossRef]

50. Everard, A.; Lazarevic, V.; Gaïa, N.; Johansson, M.; Ståhlman, M.; Bäckhed, F.; Delzenne, N.M.; Schrenzel, J.; Francois, P.; Cani, P.D. Microbiome of prebiotic-treated mice reveals novel targets involved in host response during obesity. ISME J. 2014, 8, 2116-2130. [CrossRef]

51. Schwiertz, A.; Taras, D.; Schafer, K.; Beijer, S.; Bos, N.A.; Donus, C.; Hardt, P.D. Microbiota and SCFA in Lean and Overweight Healthy Subjects. Obesity 2010, 18, 190-195. [CrossRef]

52. Daniel, S.; Kevin, W.; Megan, R.; Mark, M.; Gerald, H.; Jaimon, T.K.; Erin, R.S.; Heidi, M.S.; Katrina, L. Campbell Dietary fiber intervention on gut microbiota composition in healthy adults: A systematic review and meta-analysis. Am. J. Clin. Nutr. 2018. [CrossRef]

53. Reddy, B.S.; Hamid, R.; Rao, C.V. Effect of dietary oligofructose and inulin on colonic preneoplastic aberrant crypt foci inhibition. Carcinogenesis 1997, 18, 1371-1374. [CrossRef]

54. Pellegrini, S.; Sordi, V.; Bolla, A.M.; Saita, D.; Ferrarese, R.; Canducci, F.; Clementi, M.; Invernizzi, F.; Mariani, A.; Bonfanti, R.; et al. Duodenal Mucosa of Patients with Type 1 Diabetes Shows Distinctive Inflammatory Profile and Microbiota. J. Clin. Endocrinol. Metab. 2017, 102, 1468-1477. [CrossRef] [PubMed]

55. Morotomi, M. The Family Sutterellaceae. In Prokaryotes: Alphaproteobacteria and Betaproteobacteria; Rosenberg, E., DeLong, E.F., Lory, S., Stackebrandt, E., Thompson, F., Eds.; Springer: Berlin/Heidelberg, Germany, 2014; pp. 1005-1012. ISBN 978-3-642-30197-1.

56. Allin, K.H.; Tremaroli, V.; Caesar, R.; Jensen, B.A.H.; Damgaard, M.T.F.; Bahl, M.I.; Licht, T.R.; Hansen, T.H.; Nielsen, T.; The IMI-DIRECT consortium; et al. Aberrant intestinal microbiota in individuals with prediabetes. Diabetologia 2018, 61, 810-820. [CrossRef] [PubMed]

57. Candon, S.; Perez-Arroyo, A.; Marquet, C.; Valette, F.; Foray, A.-P.; Pelletier, B.; Milani, C.; Ventura, M.; Bach, J.-F.; Chatenoud, L. Antibiotics in Early Life Alter the Gut Microbiome and Increase Disease Incidence in a Spontaneous Mouse Model of Autoimmune Insulin-Dependent Diabetes. PLoS ONE 2015, 10, 1-16. [CrossRef] [PubMed]

58. Ding, H.T.; Taur, Y.; Walkup, J.T. Gut Microbiota and Autism: Key Concepts and Findings. J. Autism Dev. Disord. 2017, 47, 480-489. [CrossRef] [PubMed] 
59. Reddel, S.; Del Chierico, F.; Quagliariello, A.; Giancristoforo, S.; Vernocchi, P.; Russo, A.; Fiocchi, A.; Rossi, P.; Putignani, L.; El Hachem, M. Gut microbiota profile in children affected by atopic dermatitis and evaluation of intestinal persistence of a probiotic mixture. Sci. Rep. 2019, 9, 4996. [CrossRef] [PubMed]

60. Vatanen, T.; Kostic, A.D.; D’Hennezel, E.; Siljander, H.; Franzosa, E.A.; Yassour, M.; Kolde, R.; Vlamakis, H.; Arthur, T.D.; Hämäläinen, A.M.; et al. Variation in Microbiome LPS Immunogenicity Contributes to Autoimmunity in Humans. Cell 2016, 165, 842-853. [CrossRef]

61. Sun, Y.; Geng, W.; Pan, Y.; Wang, J.; Xiao, P.; Wang, Y. Supplementation with Lactobacillus kefiranofaciens ZW3 from Tibetan Kefir improves depression-like behavior in stressed mice by modulating the gut microbiota. Food Funct. 2019, 10, 925-937. [CrossRef]

62. Hamilton, A.L.; Kamm, M.A.; Ng, S.C.; Morrison, M. Proteus spp. as Putative Gastrointestinal Pathogens. Clin. Microbiol. Rev. 2018, 31, e00085-17. [CrossRef]

63. Kjeldsen-Kragh, J. Rheumatoid arthritis treated with vegetarian diets. Am. J. Clin. Nutr. 1999, 70, 594s-600s. [CrossRef]

64. Tlaskalova-Hogenova, H.; Stepankova, R.; Kozakova, H.; Hudcovic, T.; Vannucci, L.; Tučková, L.; Rossmann, P.; Hrncir, T.; Kverka, M.; Zakostelska, Z.; et al. The role of gut microbiota (commensal bacteria) and the mucosal barrier in the pathogenesis of inflammatory and autoimmune diseases and cancer: Contribution of germ-free and gnotobiotic animal models of human diseases. Cell. Mol. Immunol. 2011, 8, 110-120. [CrossRef]

65. Moon, J.-Y.; Zolnik, C.P.; Wang, Z.; Qiu, Y.; Usyk, M.; Wang, T.; Kizer, J.R.; Landay, A.L.; Kurland, I.J.; Anastos, K.; et al. Gut microbiota and plasma metabolites associated with diabetes in women with, or at high risk for, HIV infection. EBioMedicine 2018, 37, 392-400. [CrossRef] [PubMed]

66. Zhang, X.; Shen, D.; Fang, Z.; Jie, Z.; Qiu, X.; Zhang, C.; Chen, Y.; Ji, L. Human Gut Microbiota Changes Reveal the Progression of Glucose Intolerance. PLoS ONE 2013, 8, e71108. [CrossRef] [PubMed]

67. Brown, C.T.; Davis-Richardson, A.G.; Giongo, A.; Gano, K.A.; Crabb, D.B.; Mukherjee, N.; Casella, G.; Drew, J.C.; Ilonen, J.; Knip, M.; et al. Gut Microbiome Metagenomics Analysis Suggests a Functional Model for the Development of Autoimmunity for Type 1 Diabetes. PLoS ONE 2011, 6, e25792. [CrossRef] [PubMed]

68. Everard, A.; Lazarevic, V.; Derrien, M.; Girard, M.; Muccioli, G.M.; Neyrinck, A.M.; Possemiers, S.; Van Holle, A.; François, P.; De Vos, W.M.; et al. Responses of Gut Microbiota and Glucose and Lipid Metabolism to Prebiotics in Genetic Obese and Diet-Induced Leptin-Resistant Mice. Diabetes 2011, 60, 2775-2786. [CrossRef] [PubMed]

69. Everard, A.; Belzer, C.; Geurts, L.; Ouwerkerk, J.P.; Druart, C.; Bindels, L.B.; Guiot, Y.; Derrien, M.; Muccioli, G.G.; Delzenne, N.M.; et al. Cross-talk between Akkermansia muciniphila and intestinal epithelium controls diet-induced obesity. Proc. Natl. Acad. Sci. USA 2013, 110, 9066-9071. [CrossRef] [PubMed]

70. Kostic, A.D.; Gevers, D.; Siljander, H.; Vatanen, T.; Hyötyläinen, T.; Hämäläinen, A.-M.; Peet, A.; Tillmann, V.; Pöhö, P.; Mattila, I.; et al. The Dynamics of the Human Infant Gut Microbiome in Development and in Progression toward Type 1 Diabetes. Cell Host Microbe 2015, 17, 260-273. [CrossRef] [PubMed]

71. Han, K.; Luo, D.; Zou, Y.; Dong, S.; Wan, Z.; Yang, X.-Q. Modulation of Gut Microbiota by Soybean 7S Globulin Peptide That Involved Lipopolysaccharide-Peptide Interaction. J. Agric. Food Chem. 2019, 67, 2201-2211. [CrossRef]

72. Wang, L.; Li, P.; Tang, Z.; Yan, X.; Feng, B. Structural modulation of the gut microbiota and the relationship with body weight: Compared evaluation of liraglutide and saxagliptin treatment. Sci. Rep. 2016, 6, 33251. [CrossRef]

73. Murri, M.; Leiva, I.; Gomez-Zumaquero, J.M.; Tinahones, F.J.; Cardona, F.; Soriguer, F.; Queipo-Ortuño, M.I. Gut microbiota in children with type 1 diabetes differs from that in healthy children: A case-control study. BMC Med. 2013, 11, 46. [CrossRef]

74. Zhang, L.; Ouyang, Y.; Li, H.; Shen, L.; Ni, Y.; Fang, Q.; Wu, G.; Qian, L.; Xiao, Y.; Zhang, J.; et al. Metabolic phenotypes and the gut microbiota in response to dietary resistant starch type 2 in normal-weight subjects: A randomized crossover trial. Sci. Rep. 2019, 9, 4736. [CrossRef]

75. Ezaki, T.; Li, N.; Shu, S.; Zhao, L.; Kawamura, Y.; Li, Z.Y. Proposal of the genera Anaerococcus gen. nov., Peptoniphilus gen. nov. and Gallicola gen. nov. for members of the genus Peptostreptococcus. Int. J. Syst. Evol. Microbiol. 2015, 51, 1521-1528. [CrossRef] [PubMed]

76. Hänninen, A.; Toivonen, R.; Pöysti, S.; Belzer, C.; Plovier, H.; Ouwerkerk, J.P.; Emani, R.; Cani, P.D.; De Vos, W.M. Akkermansia muciniphila induces gut microbiota remodelling and controls islet autoimmunity in NOD mice. Gut 2017, 67, 1445-1453. [CrossRef] [PubMed] 
77. Zhao, S.; Liu, W.; Wang, J.; Shi, J.; Sun, Y.; Wang, W.; Ning, G.; Liu, R.-X.; Hong, J. Akkermansia muciniphila improves metabolic profiles by reducing inflammation in chow diet-fed mice. J. Mol. Endocrinol. 2017, 58, 1-14. [CrossRef] [PubMed]

78. Wang, L.; Wu, Y.; Zhuang, L.; Chen, X.; Min, H.; Song, S.; Liang, Q.; Li, A.-D.; Gao, Q. Puerarin prevents high-fat diet-induced obesity by enriching Akkermansia muciniphila in the gut microbiota of mice. PLoS ONE 2019, 14, e0218490. [CrossRef] [PubMed]

79. Shang, Q.; Wang, Y.; Pan, L.; Niu, Q.; Li, C.; Jiang, H.; Cai, C.; Hao, J.; Li, G.; Yu, G. Dietary Polysaccharide from Enteromorpha Clathrata Modulates Gut Microbiota and Promotes the Growth of Akkermansia muciniphila, Bifidobacterium spp. and Lactobacillus spp. Mar. Drugs 2018, 16, 167. [CrossRef] [PubMed]

80. Meijer, K.; de Vos, P.; Priebe, M.G. Butyrate and other short-chain fatty acids as modulators of immunity: What relevance for health? Curr. Opin. Clin. Nutr. Metab. Care 2010, 13, 715-721. [CrossRef]

81. Suzuki, T.; Yoshida, S.; Hara, H. Physiological concentrations of short-chain fatty acids immediately suppress colonic epithelial permeability. Br. J. Nutr. 2008, 100, 297-305. [CrossRef]

82. Turnbaugh, P.J.; Ley, R.E.; Mahowald, M.A.; Magrini, V.; Mardis, E.R.; Gordon, J.I. An obesity-associated gut microbiome with increased capacity for energy harvest. Nature 2006, 444, 1027-1031. [CrossRef]

83. Vrieze, A.; Van Nood, E.; Holleman, F.; Salojärvi, J.; Kootte, R.S.; Bartelsman, J.F.; Dallinga-Thie, G.M.; Ackermans, M.T.; Serlie, M.J.; Oozeer, R.; et al. Transfer of Intestinal Microbiota from Lean Donors Increases Insulin Sensitivity in Individuals with Metabolic Syndrome. Gastroenterology 2012, 143, 913-916. [CrossRef]

84. Gao, Z.; Yin, J.; Zhang, J.; Ward, R.E.; Martin, R.J.; Lefevre, M.; Cefalu, W.T.; Ye, J. Butyrate Improves Insulin Sensitivity and Increases Energy Expenditure in Mice. Diabetes 2009, 58, 1509-1517. [CrossRef]

85. Matheus, V.; Monteiro, L.; Oliveira, R.; Maschio, D.; Collares-Buzato, C. Butyrate reduces high-fat diet-induced metabolic alterations, hepatic steatosis and pancreatic beta cell and intestinal barrier dysfunctions in prediabetic mice. Exp. Boil. Med. 2017, 242, 1214-1226. [CrossRef] [PubMed]

86. Roberfroid, M.; Gibson, G.R.; Hoyles, L.; McCartney, A.L.; Rastall, R.; Rowland, I.; Wolvers, D.; Watzl, B.; Szajewska, H.; Stahl, B.; et al. Prebiotic effects: Metabolic and health benefits. Br. J. Nutr. 2010, 104, S1-S63. [CrossRef] [PubMed]

87. Yun, S.; Park, H.; Kang, J. Effect ofLactobacillus gasseriBNR17 on blood glucose levels and body weight in a mouse model of type 2 diabetes. J. Appl. Microbiol. 2009, 107, 1681-1686. [CrossRef] [PubMed]

88. Lin, H.V.; Frassetto, A.; Kowalik, E.J.; Nawrocki, A.R.; Lu, M.M.; Kosinski, J.R.; Hubert, J.A.; Szeto, D.; Yao, X.; Forrest, G.; et al. Butyrate and Propionate Protect against Diet-Induced Obesity and Regulate Gut Hormones via Free Fatty Acid Receptor 3-Independent Mechanisms. PLoS ONE 2012, 7, e35240. [CrossRef] [PubMed]

89. Kang, S.J.; Le, J.E.; Lee, E.K.; Jung, D.H.; Song, C.H.; Park, S.J.; Choi, S.H.; Han, C.H.; Ku, S.K.; Lee, Y.J. Fermentation with Aquilariae Lignum Enhances the Anti-Diabetic Activity of Green Tea in Type II Diabetic db/db Mouse. Nutrients 2014, 6, 3536-3571. [CrossRef] [PubMed]

90. Rajasekaran, A.; Kalaivani, M. Protective effect of Monascus fermented rice against STZ-induced diabetic oxidative stress in kidney of rats. J. Food Sci. Technol. 2015, 52, 1434-1443. [CrossRef] [PubMed]

91. Vilahur, G.; López-Bernal, S.; Camino, S.; Mendieta, G.; Padró, T.; Badimon, L. Lactobacillus plantarum CECT 7315/7316 intake modulates the acute and chronic innate inflammatory response. Eur. J. Nutr. 2015, 54, 1161-1171. [CrossRef]

92. Kahn, S.E. The relative contributions of insulin resistance and beta-cell dysfunction to the pathophysiology of Type 2 diabetes. Diabetologia 2003, 46, 3-19. [CrossRef]

93. Ghorbani, A.; Shafiee-Nick, R. Pathological consequences of C-peptide deficiency in insulin-dependent diabetes mellitus. World J. Diabetes 2015, 6, 145-150. [CrossRef]

94. Harris, K.; Kassis, A.; Major, G.; Chou, C.J. Is the Gut Microbiota a New Factor Contributing to Obesity and Its Metabolic Disorders? J. Obes. 2012, 2012, 1-14.

95. Tolhurst, G.; Heffron, H.; Lam, Y.S.; Parker, H.E.; Habib, A.M.; Diakogiannaki, E.; Cameron, J.; Grosse, J.; Reimann, F.; Gribble, F.M. Short-Chain Fatty Acids Stimulate Glucagon-Like Peptide-1 Secretion via the G-Protein-Coupled Receptor FFAR2. Diabetes 2012, 61, 364-371. [CrossRef] [PubMed]

96. Parekh, P.J.; Arusi, E.; Vinik, A.I.; Johnson, D.A. The Role and Influence of Gut Microbiota in Pathogenesis and Management of Obesity and Metabolic Syndrome. Front. Endocrinol. 2014, 5, 1-7. [CrossRef] [PubMed]

97. Byun, M.-S.; Yu, O.-K.; Cha, Y.-S.; Park, T.-S. Korean traditional Chungkookjang improves body composition, lipid profiles and atherogenic indices in overweight/obese subjects: A double-blind, randomized, crossover, placebo-controlled clinical trial. Eur. J. Clin. Nutr. 2016, 70, 1116-1122. [CrossRef] [PubMed] 
98. Sivamaruthi, B.S.; Kesika, P.; Prasanth, M.I.; Chaiyasut, C. A Mini Review on Antidiabetic Properties of Fermented. Nutrients 2018, 10, 1973. [CrossRef] [PubMed]

99. Naito, E.; Kounoshi, Y.; Kunihiro, S.; Yoshida, Y.; Makino, K.; Takahashi, R.; Matsuzaki, T.; Miyazaki, K.; Ishikawa, F. Beneficial effect of oral administration of Lactobacillus casei strain Shirota on insulin resistance in diet-induced obesity mice. J. Appl. Microbiol. 2011, 110, 650-657. [CrossRef] [PubMed]

100. Andersson, U.; Bränning, C.; Ahrné, S.; Molin, G.; Alenfall, J.; Önning, G.; Nyman, M.; Holm, C. Probiotics lower plasma glucose in the high-fat fed C57BL/6J mouse. Benef. Microbes 2010, 1, 189-196. [CrossRef]

101. Goldsmith, F.; O'Sullivan, A.; Smilowitz, J.T.; Freeman, S.L. Lactation and Intestinal Microbiota: How Early Diet Shapes the Infant Gut. J. Mammary Gland. Boil. Neoplasia 2015, 20, 149-158. [CrossRef]

102. Graham, C.; Mullen, A.; Whelan, K. Obesity and the gastrointestinal microbiota: A review of associations and mechanisms. Nutr. Rev. 2015, 73, 376-385. [CrossRef]

103. Cotillard, A.; Kennedy, S.P.; Kong, L.C.; Prifti, E.; Pons, N.; Le Chatelier, E.; Almeida, M.; Quinquis, B.; Levenez, F.; ANR MicroObes consortium; et al. Dietary intervention impact on gut microbial gene richness. Nature 2013, 500, 585-588. [CrossRef]

104. Paoli, A.; Rubini, A.; Volek, J.S.; Grimaldi, K.A. Beyond weight loss: A review of the therapeutic uses of very-low-carbohydrate (ketogenic) diets. Eur. J. Clin. Nutr. 2013, 67, 789-796. [CrossRef]

105. Vos, W.M.; De Vos, E.A.J. De Role of the intestinal microbiome in health and disease: From correlation to causation. Nutr. Rev. 2012, 70, S45-S56. [CrossRef] [PubMed]

106. Burke, C.; Steinberg, P.; Rusch, D.; Kjelleberg, S.; Thomas, T. Bacterial community assembly based on functional genes rather than species. Proc. Natl. Acad. Sci. USA 2011, 108, 14288-14293. [CrossRef] [PubMed]

107. Jung, S.-J.; Park, S.-H.; Choi, E.-K.; Cha, Y.-S.; Cho, B.-H.; Kim, Y.-G.; Kim, M.-G.; Song, W.O.; Park, T.-S.; Ko, J.-K.; et al. Beneficial effects of Korean traditional diets in hypertensive and type 2 diabetic patients. J. Med. Food 2014, 17, 161-171. [CrossRef] [PubMed]

108. Ebringer, L.; Ferenčík, M.; Krajčovič, J. Beneficial Health Effects of Milk and Fermented Dairy. Folia Microbiol. 2008, 53, 378-394. [CrossRef]

109. Niibo, M.; Shirouchi, B.; Umegatani, M.; Morita, Y.; Ogawa, A.; Sakai, F.; Kadooka, Y.; Sato, M. Probiotic Lactobacillus gasseri SBT2055 improves insulin secretion in a diabetic rat model. J. Dairy Sci. 2019, 102, 997-1006. [CrossRef] [PubMed]

110. Ramos, C.L.; Thorsen, L.; Schwan, R.F.; Jespersen, L. Strain-specific probiotics properties of Lactobacillus fermentum, Lactobacillus plantarum and Lactobacillus brevis isolates from Brazilian food products. Food Microbiol. 2013, 36, 22-29. [CrossRef] [PubMed]

111. Sanders, M.E.; Guarner, F.; Guerrant, R.; Holt, P.R.; Mm, E. An update on the use and investigation of probiotics in heath and disease. Gut 2015, 62, 787-796. [CrossRef] 